
\title{
Research S Surate \\ Influence of Tibetan Plateau On The North American Summer Monsoon Precipitation
}

\author{
Qin Wen ( $\nabla$ wenq@pku.edu.cn ) \\ Zixuan Han \\ Hohai University \\ Hajun Yang \\ Fudan University \\ Jianbo Cheng \\ Yancheng Institute of Technology \\ Zhengyu Liu \\ Ohio State University \\ Jian Liu \\ Nanjing Normal University
}

Nanjing Normal University https://orcid.org/0000-0003-0858-3864

\section{Research Article}

Keywords: Tibetan Plateau, North American summer monsoon, Hadley circulation, Atlantic meridional overturning circulation, Intertropical Convergence Zone

Posted Date: March 12th, 2021

DOI: https://doi.org/10.21203/rs.3.rs-264225/v1

License: (c) (1) This work is licensed under a Creative Commons Attribution 4.0 International License.

Read Full License 


\section{Precipitation}

${ }^{1}$ School of Geography, Nanjing Normal University, Nanjing, 210023, China; Key Laboratory of Virtual Geographic Environment (Nanjing Normal University), Ministry of Education, Nanjing, 210023, China; Jiangsu Center for Collaborative Innovation in Geographical Information Resource Development and Application, Nanjing, 210023, China

${ }^{2}$ Open studio for Ocean-Climate-Isotope Modeling, Pilot National Laboratory for Marine Science and Technology (Qingdao), Qingdao, 266100, China

\section{${ }^{3}$ College of Oceanography/Key Laboratory of Marine Hazards Forecasting, Ministry of Natural} Resources/Key Laboratory of Ministry of Education for Coastal Disaster and Protection, Hohai University, Nanjing, 210024, China

${ }^{4}$ Department of Atmospheric and Oceanic Sciences, Institute of Atmospheric Science and CMA-FDU Joint Laboratory of Marine Meteorology, Fudan University, Shanghai, 200438, China ${ }^{5}$ School of Environmental Science and Engineering, Yancheng Institute of Technology, Yancheng

$21{ }^{7}$ Jiangsu Provincial Key Laboratory for Numerical Simulation of Large Scale Complex Systems, School of Mathematical Science, Nanjing Normal University, Nanjing 210023, China 
25 *Corresponding author address: Qin Wen, School of Geography, Nanjing Normal University, 26 Nanjing, China, 210023.

27 Email: wenq@pku.edu.cn 


\section{Abstract}

It has been well known that the uplift of the Tibetan Plateau (TP) can significantly enhance the

30 Asian monsoon. Here, by comparing the sensitivity experiments with vs without the TP, we find that

31 TP uplift can also increase the precipitation of North American Summer Monsoon (NASM), with

32 atmosphere teleconnection accounting for $6 \%$ and oceanic dynamical process accounting for another

$336 \%$. Physically, TP uplift generates a stationary Rossby wave train traveling from Asian continent to

34 the North Atlantic region, resulting in an anomalous high-pressure over tropical-subtropical North

35 Atlantic. The anomalous subtropical high enhances the low level southerly winds, forcing an

36 anomalous upward motion over North American monsoon (NAM) region and then an increased

37 summer precipitation there. In addition, TP uplift enhances the Atlantic meridional overturning

38 circulation, which reduces the meridional temperature gradient and leads to a northward shift of

39 Hadley Cell over eastern Pacific-Atlantic section. The latter shifts the convection center northward to

$4010^{\circ} \mathrm{N}$ and further increases the NASM precipitation. The enhanced NASM precipitation can also be

41 understood by the northward shift of Intertropical Convergence Zone. Our study implies that the

42 changes of NAM climate can be affected by not only local process but also remote forcing, including

43 the Asian highland.

47 Keywords Tibetan Plateau · North American summer monsoon · Hadley circulation · Atlantic

48 meridional overturning circulation - Intertropical Convergence Zone 


\section{Introduction}

The uplift of the Tibetan Plateau (TP) has been known to generate a great impact on regional climate change, especially for monsoon climate, although the precise history of the TP uplift is still controversial (Harrison et al., 1992; An, 2001; Molnar et al., 2010). For example, the monsoon intensity over South Asian shows a correlation with the rate of Himalayan exhumation over the past 23 Myr (Million years) (Clift, 2008). The enhanced southwesterly winds, documented by the planktonic foraminifer over Arabian Sea, indicating the strengthening of Indian summer monsoon about 9-8 Myr ago (Kroon et al., 1991; Prell et al., 1992, 1997). New basal dates from the aeolian "Red Clay" sediments on the Chinese Loess plateau indicate onset of aeolian dust accumulation at about 7.6 Myr ago (An et al., 2001). The change in oxygen isotope composition of soil carbonates in Pakistan infers changes in vegetation from forests to grasses in Pakistan beginning about 8 Myr ago (Quade et al., 1989), and a change from mixed needle-leaf or broad-leaf forests to grassland vegetation along the northeastern margin of the TP about 8.5 Myr ago (Cerling et al., 1997), which indicates increased summer precipitation.

Until now, the TP uplift on Asian monsoon has been studied extensively. Several studies investigate the Asian summer monsoon behavior under the TP elevation forcing (Boos and Kuang, 2010; Park et al., 2012; Wu et al., 2012). Major results were that the uplift of the TP significantly increases the Asian monsoon intensity (Prell and Kutzbach, 1992) and variability (Fallah et al., 2016). Considering different stages of TP uplift, Jiang et al (2008), as well as Liu and Yin (2002) find that an East Asian summer monsoon system similar to that of the present initially exists when the TP uplift $60 \%$ of its modern height and is gradually intensified with the continued plateau uplift. An et al. (2001) confirm the linkage of stages in evolution of Asian monsoons to the phases of the Himalaya-Tibetan plateau uplift. In addition, the uplift of different parts of the TP on distinct Asian monsoon climate has also been verified by recent numerical experiments (Zhang et al., 2010; Tang et al., 2013). Boos and Kuang (2010) reveal that the large-scale South Asian summer monsoon circulation is unaffected by 
74 removal of the plateau, instead, it depends on the exists of narrow orography of the Himalayas and

75 adjacent mountain. This has also been confirmed by Wu et al (2012), in which they suggest that the 76 mechanical effect of the plateau is not the major driver of the Asian summer monsoon.

77 However, few studies have focused on the impact of the TP topography on North American monsoon (NAM) climate. Dominated by perennially dry conditions, the NAM contributes approximately 40 and $70 \%$ of the annual total precipitation for the southwest Unite States and northwest Mexico, respectively (Higgins et al., 1997). The NAM is associated with anomalous westerlies to the southwest of the anomalous cyclone transporting water vapor from the eastern tropical Pacific and the Gulf of California, characterized by a local cyclonic anomaly with distinct rainfall maxima over western Mexico (Yim et al., 2014).

The motivation for this study is that, contrast to Asian monsoon region located to the west of the Pacific Ocean, the NAM region is located over eastern Pacific Ocean and close to Atlantic Ocean. Some works suggest an intercontinental contrasting precipitation anomaly between Asia and North America, that is, the extensive precipitation increase over Asian monsoon regions always accompanies with droughts over North America (Zhao et al., 2016). So, we wonder if the TP uplift could generate this feature since the TP uplift produces massive summer precipitation increase over Asian monsoon region. In addition, previous works demonstrate that the negative SST anomalies in the North Atlantic can substantially alter the North Atlantic subtropical high, which may ultimately influence the NAM

92 (Kushnir et al., 2010; Parsons et al., 2014; Wang et al., 2014). The NAM is also closely linked to 93 tropical Pacific sea surface temperature (Castro et al., 2001). The positive temperature anomaly over 94 eastern-central Pacific can displace the North Pacific intertropical convergence zone and the South 95 Pacific convergence zone equatorward, thereby directly reducing the NAM rainfall (Webster et al., 96 1998; Wang et al., 2012).

Our previous works suggest that the TP uplift may enhance the trade winds over the Pacific Ocean and the establishment of the Atlantic meridional overturning circulation (Wen and Yang, 2020; Yang 
and Wen, 2020). How would the North American summer monsoon (NASM) precipitation may change

100 under the TP uplift? This question has rarely been addressed in previous works. Here, we will examine

101 the evolution of the NASM and its mechanisms by checking the atmospheric process and oceanic

102 feedbacks, which has never been addressed before.

103 This paper is arranged as follows. An introduction to the model and experiments, as well as the

104 methods is given in section 2. Changes in mean climate and NASM precipitation are illustrated in

105 section 3. Mechanisms for NASM precipitation change are analyzed in section 4. Summary and

106 discussion are given in section 5.

107 2. Model and methods

$108 \quad 2.1 \quad$ Model and experiments

109 The Community Earth System Model (CESM1.0) is applied in this study. This model has been

110 widely used to study the Earth's past, present, and future climate states (http://www2.cesm.ucar.edu/).

111 CESM was developed by the U.S. National Centre for Atmospheric Research (NCAR) and is

112 composed of atmosphere model (Community Atmosphere Model; CAM5), ocean model (Parallel

113 Ocean Program; POP2), land surface model (Community Land Model; CLM4), sea ice model

114 (Community Ice Code; CICE4) components and one coupler (CPL7). Detailed model descriptions can

115 be found in Wen and Yang (2020).

116 To detailly assess the TP uplift on NASM precipitation, we separate the atmospheric and

117 oceanic dynamical process by conducting two groups of simulations using CESM low resolution

118 (T31_g37) configuration. The first group is fully coupled run, including a 2400-year real simulation

119 and a 400-year no-mountain run. The real simulation is named "CTRL", in which the model

120 geometry, topography, and continents are realistic (Fig. 1a). The CTRL run reaches equilibrium state

121 around 2000 years (Yang et al. 2015). The sensitive run (named "NoTP”) starts from the year 2001 of 
122 CTRL, and is integrated for 400 years with the topography around the TP set to 50m above the sea

123 level (Fig. 1b). Except the topography elevation, all other boundary conditions, such as vegetation and

124 albedo remain unmodified and they are free adjusted. The second group is slab ocean (SOM) run, in

125 which the ocean dynamical process has been shut-down and replaced by a mixed layer from the

126 climatology of CTRL simulation. Two experiments in this group are named "CTRL_SOM" and

127 "NoTP_SOM", in which the topography is set as that in "CTRL" and "NoTP", respectively.

128 "CTRL_SOM" is integrated for 400 years and "NoTP_SOM" starts from the year 201 of

129 "CTRL_SOM" and is integrated for 200 years. The equilibrium changes are deduced by using data

130 from the last 100 years of each experiments. The difference between the "CTRL" and "NoTP" is for

131 the sum of atmospheric and oceanic dynamical process, and the difference between the

132 "CTRL_SOM" and "NoTP_SOM" can be treated as atmospheric effect.

\subsection{North American monsoon region}

134 According to Wang and Ding (2008), the NAM domain is delineated by the region in which the

135 local summer precipitation minus local winter precipitation exceeding $2 \mathrm{~mm} /$ day and the local summer

136 precipitation exceeds $55 \%$ of annual rainfall. Based on this definition, the NAM regions are clearly

137 shown in Fig. 3d by using the GPCP data (outlined by purple contours). The monsoon regions

138 obtained by CESM CTRL simulation are similar to the GPCP's results (outlined by black contours),

139 which is also shown in Liu et al (2016). The NAM domain obtained in this study is primarily based

140 on precipitation contrast in the solstice seasons and is larger than that traditionally recognized by

141 many scientists working on the NAM (Wang et al., 2021). The NASM precipitation can be obtained

142 by the weighted-area average local summer precipitation over the NAM area.

\section{$143 \quad 2.3$ Moisture budget}


144 To reveal the mechanisms that govern changes in NASM precipitation related to the TP uplift, 145 we analyse changes in the moisture budget according to Chou et al. (2009):

$$
P^{\prime}=E^{\prime}-\bar{\omega} \frac{\partial q^{\prime}}{\partial p}-\omega^{\prime} \frac{\partial \bar{q}}{\partial p}-\left\langle\bar{V} \cdot \nabla q^{\prime}\right\rangle-\left\langle V^{\prime} \cdot \nabla \bar{q}\right\rangle+R
$$

147 Here, $P$ is precipitation, $E$ is surface evaporation, $\omega$ is vertical velocity, $q$ is specific

148 humidity, $p$ is pressure, $V$ is horizontal wind vector, $R$ is residual. Overbars represent monthly

149 means in CTRL, and primes denote the difference between CTRL and NoTP. Based on this equation,

150 the monsoon precipitation change can be decomposed into evaporation change ( $\left.E^{\prime}\right)$, the

151 thermodynamic and dynamic changes of vertical moisture advection $\left(-\bar{\omega} \frac{\partial q^{\prime}}{\partial p}\right.$ and $\left.-\omega^{\prime} \frac{\partial \bar{q}}{\partial p}\right)$, and 152 thermodynamic and dynamic changes of horizontal moisture advection $\left(-\left\langle\bar{V} \cdot \nabla q^{\prime}\right\rangle\right.$ and $\left.-\left\langle V^{\prime} \cdot \nabla \bar{q}\right\rangle\right)$ 153 and the residual $R$.

$154 \quad 2.4$ Three-pattern decomposition of global atmospheric circulation

155 The monsoon circulation is the component of large-scale atmospheric motion. The large-scale 156 atmospheric motion to first order is consist of Rossby wave at mid-high latitudes (Rossby, 1939), 157 Hadley and Walker circulation at low latitudes (Trenberth and Solomon, 1994; Julian and Chervin, 158 1978). However, these components interact with each other and is hard to be distinguished in the real 159 world. Fortunately, a new method named the three-pattern decomposition of global atmospheric 160 circulation (3P-DGAC) has been introduced by $\mathrm{Hu}$ et al (2017), by which the global atmospheric 161 circulation $\vec{V}$ is decomposed into the horizontal circulation $\left(\vec{V}_{R}^{\prime}\right)$, meridional circulation $\left(\vec{V}^{\prime}{ }_{H}\right)$ and 162 zonal circulation $\left(\vec{V}^{\prime}{ }_{W}\right)$ as follows,

$$
\vec{V}^{\prime}=\vec{V}_{H}^{\prime}+\vec{V}_{W}^{\prime}+\vec{V}_{R}^{\prime}
$$

164 in which, 


$$
\begin{gathered}
\left\{\begin{array}{l}
\vec{V}^{\prime}{ }_{R}(\lambda, \theta, \sigma)=u^{\prime}{ }_{R}(\lambda, \theta, \sigma) \vec{\imath}+v^{\prime}{ }_{R}(\lambda, \theta, \sigma) \vec{\jmath} \\
\vec{V}^{\prime}{ }_{H}(\lambda, \theta, \sigma)=v^{\prime}{ }_{H}(\lambda, \theta, \sigma) \vec{\jmath}+\dot{\sigma}_{H}(\lambda, \theta, \sigma) \vec{k} \\
\vec{V}^{\prime}{ }_{W}(\lambda, \theta, \sigma)=u^{\prime}{ }_{W}(\lambda, \theta, \sigma) \vec{\imath}+\dot{\sigma}_{W}(\lambda, \theta, \sigma) \vec{k}
\end{array}\right. \\
\left\{\begin{array}{c}
u^{\prime}{ }_{R}=-\frac{\partial R}{\partial \theta}, v^{\prime}{ }_{R}=\frac{1}{\sin \theta} \frac{\partial R}{\partial \lambda} \\
v^{\prime}{ }_{H}=-\frac{\partial H}{\partial \sigma}, \dot{\sigma}_{H}=\frac{1}{\sin \theta} \frac{\partial(\sin \theta H)}{\partial \theta} \\
u_{W}^{\prime}=\frac{\partial W}{\partial \sigma}, \dot{\sigma}_{W}=-\frac{1}{\sin \theta} \frac{\partial W}{\partial \lambda}
\end{array}\right.
\end{gathered}
$$

167 Where $(\lambda, \theta, \sigma)$ is the spherical $\sigma$-coordinate system, $\left(u_{R}^{\prime}, v^{\prime}{ }_{R}\right),\left(v^{\prime}{ }_{H}, \dot{\sigma}_{H}\right)$ and $\left(u_{W}^{\prime}, \dot{\sigma}_{W}\right)$ are the wind 168 vector components of horizonal circulation, meridional circulation, and zonal circulation, respectively. $R, H$, and $W$ are the stream functions which can be obtained from following equation:

$$
\frac{\partial W}{\partial \sigma}=\frac{\partial R}{\partial \theta}+u^{\prime}
$$

Where $\Delta_{3}=\frac{1}{\sin ^{2} \theta} \frac{\partial^{2}}{\partial \lambda^{2}}+\frac{1}{\sin \theta} \frac{\partial}{\partial \theta}\left(\sin \theta \frac{\partial}{\partial \theta}\right)+\frac{\partial^{2}}{\partial \sigma^{2}}$ is the three-dimensional Laplacian in the spherical $\sigma$-coordinates and $\zeta=\frac{1}{\sin \theta} \frac{\partial v^{\prime}}{\partial \lambda}-\frac{1}{\sin \theta} \frac{\partial\left(u^{\prime} \sin \theta\right)}{\partial \theta}$ is the vertical vorticity of the entire atmospheric layer. $\left(u^{\prime}, v^{\prime}, \dot{\sigma}\right)$ represent the three velocity components in the spherical $\sigma$-coordinate system.

\section{Changes in mean climate and NASM precipitation}

To better understand the response of NASM precipitation to the TP uplift, the mean climate change are firstly examined here. The TP uplift immediately induces anticyclonic geopotential height anomalies to the north of the TP area and over the tropical-subtropical North Atlantic, and cyclonic anomalies to the south of the TP area, extending to subpolar Pacific and subpolar Atlantic (Fig. 2b).

182 The atmospheric circulation changes are roughly barotropic since the wave pattern at $500 \mathrm{hPa}$ shows 
183 resemblance to that at $850 \mathrm{hPa}$ (Yang and Wen, 2020). The adjustment of planetary wave pattern is

184 very fast and is also confirmed by our CAM5 model simulation (Figure not shown). More importantly,

185 the atmospheric responses do not change much from SOM runs to fully coupled runs (Fig. 2b vs 2d),

186 indicating that the oceanic dynamical process in the hundreds of years latter do not have considerable

187 feedback to the atmospheric circulation. Detailed atmospheric circulation changes are also discussed

188 in Yang et al (2020), which states that the teleconnection patterns in Fig. 2a and Fig. 2d agree well

189 with those in previous studies (Zhao et al., 2007, 2012) and can be well understood by the classic

190 planetary wave theory in a linear quasigeostrophic system (Hoskins and Karoly, 1981).

191 The anomalous high pressure over the tropical-subtropical North Atlantic strengthens the trade

192 winds over the tropical eastern Pacific-Atlantic section, which promotes the surface sensible heat loss

193 (Figure not shown) and results in cold surface air temperature (SAT) anomaly in SOM runs (Fig. 2c).

194 In fully coupled runs, the strengthened trade winds over the tropical eastern Pacific-Atlantic section

195 can brings the cold subsurface water upward and further cools the SAT (Fig. 2e). In addition, the

196 uplift of the TP can also lead to the establishment of the AMOC (Fig. 2a) by inducing more water

197 vapor transport from the North Atlantic to Pacific Ocean (Yang and Wen, 2020). The establishment

198 of the AMOC warms the North Atlantic by generating pronounced heat transport from Southern

199 Hemisphere (SH) to Northern Hemisphere (NH) (Fig. 2e).

The time evolution of changes in NASM precipitation under the TP uplift are shown in Fig. 3a.

201 The TP uplift immediately results in NASM precipitation increase by $0.5 \mathrm{~mm} /$ day $(6 \%)$. This can be

202 seen from the SOM runs (light blue curve) or the fully coupled runs during the first several decades

203 (blue curve) when the oceanic dynamical process is not fully responded. The oceanic dynamical

204 feedback further doubles the NASM precipitation change and leads to precipitation increase to 0.9

$205 \mathrm{~mm} /$ day (12\%). The spatial distribution of monsoon precipitation is shown in Fig. $3 \mathrm{~b}$ and $\mathrm{d}$. The 
206

207

208

209

210

211

212

213

214

215

216

217

218

219

220

221

222

223

224

225

226

227

228

NAM region is characterized by a large extent of significant summer precipitation increase via atmospheric process (Fig. 3b) and is further amplified by oceanic dynamical feedback (Fig. 3d). It is interesting to note that the precipitation is consistently increased over the NAM region by atmospheric process (Fig. 3b) while the precipitation change induced by oceanic dynamical process exhibits an out-of-phase pattern with large precipitation increase occurred over central to north NAM region and decrease over south NAM region (Fig. 3d). The changes in surface humidity are also checked here (Fig. 3c and e). The surface air humidity is slightly increased over NAM region in SOM runs (Fig. 3c). In fully coupled runs, the surface air humidity change over NAM region shows a similar pattern to precipitation change, with increase over central to north NAM region and decrease over south NAM region (Fig. 3e). In this study, the temperature is decreased over NAM region (Fig. 2c and e). Usually, the surface air cooling can suppress the convection and result in less precipitation (Xie et al., 2010), followed by drier air. The inconsistency between surface air temperature and precipitation (humidity) change here indicates that the thermal process may not important in shaping the final precipitation and humidity change.

\section{Mechanisms for NASM precipitation change}

\subsection{Moisture budget}

To understand the processes that drive the NASM precipitation change, the projected changes in precipitation and the first five terms on the right-hand side of Eq. (1) are shown in Fig. 4 and Fig. 5. Note that since we use 100-year data, all variables with color shadings are exceeding $95 \%$ confidence level determined by a two-tailed Student's t test. For simplifying the figure, we do not add stippling anymore. It is obvious that the dynamic change of vertical moisture advection is the largest contributor to the increased NASM precipitation both in SOM runs and fully coupled runs, with the magnitude in fully coupled runs much bigger than that in SOM runs (Fig. 4d and Fig. 5d). The 
enhanced vertical moisture advection is due to the increased upward motion, a point to be returned

230 later. The evaporation term is hardly changed because the TP-uplift induced surface temperature

231 change over this region is small (Fig. $2 \mathrm{c}$ and e). The weak temperature change also contributes to the

232 hardly changed thermodynamic component of vertical moisture advection (Fig. 4c and Fig. 5c). The

233 thermodynamic and dynamic changes in horizontal moisture advection are both uncertain and small

234 over NAM region (Fig. 4e, f and Fig. 5e, f), consistent with previous studies that the horizontal

235 moisture advection is usually less important than vertical moisture advection to precipitation (Chou et

236 al., 2009; Zhang et al., 2017). The contribution of these terms to NASM precipitation change are

237 summarized in Fig. 6a. The dynamic change of vertical moisture advection term nearly contributes

$238100 \%$ precipitation increase in SOM runs and fully coupled runs, respectively, which is undoubtable

239 the dominant term for NASM precipitation change. Based on Eq. (2)-Eq. (7), the dynamic change of

240 vertical moisture advection term can be further break into vertical moisture advection due to

241 meridional circulation and zonal circulation change (Fig. 6b). It is obvious that the increased dynamic

242 change of vertical moisture advection term $\left(-\left\langle\omega^{\prime} q\right\rangle\right)$ largely comes from meridional circulation

243 change $\left(-\left\langle\omega_{H}{ }^{\prime} q\right\rangle\right)$. The zonal circulation change appears to suppress the NASM precipitation increase $244 \quad\left(-\left\langle\omega_{W}^{\prime} q\right\rangle\right)$

2454.2 Mean vertical velocity and 3P-DGAC

To understand the atmospheric circulation change, the mean atmospheric vertical velocity are

247 first shown in Fig. 7. In the annual mean state of observations, the large-scale upward motion is 248 expected in the tropics, with centers near equatorial Africa, the Indian Ocean, the western Pacific, the 249 eastern Pacific, the South America, and the Atlantic Ocean (Chen et al., 2014; Cheng et al., 2020). 250 These features are also captured in our CTRL simulation (Fig. 7a). Strong upward motion in the 251 tropics is associated with deep convection and corresponds to above-normal precipitation in these 
252

253

254

255

256

257

258

259

260

261

262

263

264

regions while strong descending motion in the subtropics suppresses the convection and corresponds to the aridity (Chen et al., 2014). Thus, the equatorial Africa, the Indian Ocean, the western Pacific, the eastern Pacific, South America, and the Atlantic Ocean are characterized by a stronger precipitation than other regions (Fig. 8a). Compared to CTRL simulation, the CTRL_SOM exhibits weakened upward motion (Fig. 7c), suggesting that the ocean dynamics are important for shaping the atmospheric convection. As a consequence, the precipitation is much lower in CTRL_SOM compared with that in CTRL (Fig. 8c vs 8a). During boreal summer, the upward motion gets stronger in NH and weaker in SH (Fig. 7e-h compared with Fig. 7a-d), indicating the large scale shifts of Intertropical Convergence Zone (ITCZ) (Fig. 8e-h compared with Fig. 8a-d). Comparing CTRL_SOM and NoTP_SOM, the upward motion seems strengthened over NAM region (Fig. $7 \mathrm{~g}$ and $\mathrm{h}$ ), resulting in more precipitation over NAM region (Fig. 8g and h). Comparing CTRL and NoTP, the TP uplift leads to a northward shift of the maximum upward motion over NAM region (Fig. 7e and f), indicating a northward shift of maximum precipitation over this region (Fig. 8e and f).

Previous works suggest that the tropical overturning circulation consists of a couple of orthogonal overturning circulation, that is, meridional and zonal circulations (Hu et al., 2018). Based on 3P-DGAC method, the vertical wind can be decomposed into two parts, the vertical winds related to meridional circulation and zonal circulation. i.e., $\omega=\omega_{H}+\omega_{W}$, where $\omega$, $\omega_{H}$ and $\omega_{W}$ represent the total vertical wind, the vertical wind of meridional circulation and that of zonal circulation, respectively (Hu et al., 2018). From Fig. $9 \mathrm{~b}$ and f, we can see that the vertical wind of meridional component shares the identical center to total vertical wind (Fig. 9a vs b and Fig. 9e vs f), indicating the ascending branch of regional Hadley circulations (Cheng et al., 2020). All these regional Hadley circulations are characterized by two circulations with rising branch in the tropical regions and sinking branch in the subtropics of both hemispheres (Fig. 9b and f). For zonal circulation, there are three main centers over the Indian Ocean, the western Pacific Ocean and the western 
276

277

278

279

280

281

282

283

284

285

286

287

288

289

290

291

292
Atlantic Ocean, representing the three rising branches of Walker circulation (Fig. 9c and g). The sinking branches of Walker circulation are located in the western Indian Ocean, the eastern Pacific Ocean and the eastern Atlantic Ocean (Hu et al., 2017). The residual term is very small and can be negligible in latter discussion (Fig. 9d and h). The decomposition of vertical velocity is identical to previous works (Hu et al., 2017; Cheng et al., 2020). By using this method, we can analyze the regional meridional circulation and zonal circulation. The traditional method to define the Hadley circulation is based on the zonal average, so the contribution of the zonal component vanishes $\left[\omega_{W}=\right.$ $0]$ and $[\omega]$ contains only $\left[\omega_{H}\right]$. Thus, it is appropriate to use zonal averaged total vertical velocity to represent the Hadley circulation in the previous studies (Wen et al., 2018). However, it is incorrect to use regional total vertical velocity, i.e., the vertical wind between $80^{\circ} \mathrm{W}$ and $10^{\circ} \mathrm{W}$ to represent the regional Hadley circulation since the $\omega_{W}$ is not zero (Fig. 9c and g). In addition, the traditional definition of the Walker circulation is restricted to the tropical region and $\langle\omega\rangle_{5^{\circ} S}^{5^{\circ} N}$ is often used to calculate the Walker circulation. In this case, the $\left\langle\omega_{H}\right\rangle_{5^{\circ} S}^{{ }^{\circ} N} \neq 0$ (Fig. $7 \mathrm{~b}$ and f), which means that the contribution of the meridional circulation is included in the vertical velocity of the Walker circulation. So, when analyzing the meridional circulation (zonal circulation), the vertical wind of meridional component (zonal component) should be used.

\subsection{Mechanisms for NASM precipitation change}

The changes in vertical velocity and its meridional component and zonal component during boreal summer are shown in Fig. 10 to illustrate the mechanisms that govern the NASM precipitation response. The NAM region is characterized by an anomalous ascending motion, which is dominated by the meridional circulation change both in SOM runs and fully coupled runs (Fig. 10b and e). However, as mentioned in Section 4.2, the mechanisms may be different. In SOM runs, the TP uplift generates anomalous upward motion of meridional component over NAM region and its surrounding 
regions, which dominates the total vertical wind change (Fig. 10b) and results in increased NASM

300 precipitation (Fig. 6b). Compared to SOM runs, the anomalous upward motion in fully coupled runs

301 is located further north with abnormal descending motion at the south tip of it, indicating that the

302 meridional circulation shifts northward (Fig. 10e). The changes in upward motion of zonal component

303 over NAM region is very small and uncertain compared with that of meridional component.

304 4.3.1 Mechanisms in SOM runs: The atmospheric teleconnection response

The change in meridional component of vertical velocity over NAM region refers to the regional

Hadley circulation (HC) response. Here, we define the regional HC over eastern Pacific-Atlantic sector as spanning $120^{\circ} \mathrm{W}-20^{\circ} \mathrm{W}$ (red box in Fig. 10b and e) and plot it in Fig. 11. In SOM runs, the summer $\mathrm{HC}$ gets strengthened in both hemispheres under the TP uplift with the magnitude in NH much stronger than that in SH (Fig. 11a). The strengthened $\mathrm{HC}$ in NH results in enhanced convection over NAM region and thus the increased summer precipitation (Fig. 6b). The strengthened regional

$311 \mathrm{HC}$ in SOM runs is related to the adjustment of planetary waves (Fig. 2b). The anomalous positive

312 geopotential height over tropical-subtropical North Atlantic is accompanied by the northeasterly wind

313 at the south tip of it, which results in stronger regional $\mathrm{HC}$ over NAM region by enhancing the

314 horizontal momentum flux from the surface into the atmosphere (Cook et al., 2003). Actually, the

315 negative-positive geopotential anomaly over the North Atlantic is not unlike the positive phase of the

316 North Atlantic oscillation, which is always associated with the enhanced HC (Wang et al., 2004;

317 Cook et al., 2003; Iqbal et al., 2019).

318 4.3.2 Mechanisms in fully coupled runs: The indirect impact from the altered AMOC

319 In fully coupled runs, the TP uplift induces a northward shift of $\mathrm{HC}$ in $\mathrm{NH}$, resulting in increased 320 upward motion over the NAM region (Fig. 11c and d). The northward shift of HC in fully coupled 
runs can be understood by the meridional temperature gradient change. The uplift of the TP induces

322 the establishment of AMOC (Fig. 2a), which brings substantial heat northward to warms the $\mathrm{NH}$,

323 especially over the North Atlantic. The profound warming over mid-high latitudes reduces the

324 meridional temperature gradient, which leads to a northward shift of HC (Bush and Philander, 1999;

325 Yang et al., 2017; D'Agostino et al., 2017; Liu and Zhou, 2017). Actually, there is close coupling

326 between sea surface temperature and precipitation in the tropics (Xie et al., 2010). Over the eastern

327 Pacific-Atlantic section in fully coupled runs, the SST warming is occurred north of $10^{\circ} \mathrm{N}$ while

328 cooling is occurred south of $10^{\circ} \mathrm{N}$ (Fig. 12c). The asymmetric SST change and thus the weakened

329 meridional temperature gradient lead to a profound upward motion around $10^{\circ} \mathrm{N}$ in the real world

330 (Fig. 7e), otherwise the upward motion is located further south (Fig. 7f). This is consistent with the

331 northward shift of precipitation (Fig. 12c). However, in SOM runs, the meridional temperature

332 change is relatively small, so the HC hardly shifts.

333 The northward shift of precipitation in fully coupled runs can also be understood by regional

334 ITCZ shift. The ITCZ position are shown in Fig. 12. For eastern Pacific-Atlantic section, the mean

335 position of ITCZ in CTRL_SOM, NoTP_SOM, CTRL and NoTP during boreal summer are at $6.65^{\circ} \mathrm{N}$,

$3366.70^{\circ} \mathrm{N}, 5.91^{\circ} \mathrm{N}$ and $3.47^{\circ} \mathrm{N}$, respectively. Thus, there is nearly no shift of ITCZ in SOM runs while

337 the ITCZ shifts northward by $2.44^{\circ} \mathrm{N}$ in fully coupled runs under the TP uplift. The northward shift of

338 ITCZ in fully coupled runs results in substantially precipitation increase over central to north NAM

339 region and decrease over the south tip of NAM region (Fig. 12d). The northward shift of ITCZ over

340 the eastern Pacific-Atlantic section is related to regional atmospheric energy budget (Boos and Korty,

341 2016; Lintner and Boos, 2019). The energy input into atmosphere is shown in Fig. 13. In fully

342 coupled runs, the TP uplift causes the net energy gain of the atmosphere in the NH, especially over

343 the North Atlantic (Fig. 13a). The increase of the net energy input into the atmosphere over the North

344 Atlantic comes from both the top-of-atmosphere (TOA) and surface. In details, the energy gain at the 
345 TOA over the North Atlantic mainly comes from the shortwave radiation. The establishment of the

346 AMOC warms the North Atlantic, which reduces the low clouds and enable more shortwave can

347 come into the atmosphere (Figure not shown). Meanwhile, the energy gain at the surface mainly

348 comes from the increased longwave radiation and latent heat flux into atmosphere (Figure not shown).

349 The profound warming over North Atlantic induced by AMOC allows more longwave radiation loss

350 from ocean to atmosphere. The warming can also enhance the ocean surface evaporation and thus the

351 latent heat flux into atmosphere. In contrast to the profound energy gain in $\mathrm{NH}$, the $\mathrm{SH}$ exhibits an

352 energy loss since the setup of AMOC can generate bipolar seesaw phenomenon with warming in the

$353 \mathrm{NH}$ and cooling in the SH. The South Ocean cooling leads to more sensible and latent heat flux

354 transport from atmosphere to ocean, which results in energy loss in the SH (Figure not shown). The

355 inter-hemispheric energy asymmetry over eastern Pacific-Atlantic section results in an increase of

356 southward atmospheric energy transport occurred over the tropics (Fig. 13d), which is consistent with

357 the revealed northward shift of the ITCZ (Fig. 12d). In addition, the atmospheric energy transport

358 over tropics largely depends on the mean circulation change, i.e., the HC. Thus, the anomalous

359 southward energy transport is completed by the northward shift the HC (Fig. 11c). On the contrary,

360 the inter-hemispheric energy asymmetry is very small in SOM runs and the HC hardly shifts.

361 5. Summary and discussion

In this study, the impact of TP topography on NASM precipitation is investigated in SOM runs

363 and fully coupled runs. TP uplift is found to enhance the NASM both directly via the atmospheric

364 teleconnection and indirectly via the impact of the altered AMOC. First, the TP uplift alters the

365 planetary wave patterns and generate enhanced Atlantic subtropical high, which strengthens the

366 north-easterly wind over tropical eastern Pacific-Atlantic section and thus the enhanced regional HC

367 there. The strengthened upward motion leads to enhanced convection and thus the increased NASM 
precipitation. These processes are completed within several decades due to atmospheric adjustment.

369 Second, the TP uplift can also enhance the NASM rainfall indirectly by first enhancing the AMOC,

370 which reduces the meridional temperature gradient, leading to a northward shift of the HC. The

371 northward shift of the $\mathrm{HC}$ shifts the center of the ascending motion northward to $10^{\circ} \mathrm{N}$ and

372 substantially enhance the convection over the NAM region, and then, the NASM precipitation. This

373 study shows a robust relationship between the topography of the TP and NASM precipitation,

374 complimentary to previous perspective that TP uplift can substantially change rainfall over the Asian

375 monsoon region.

The topography of the TP in shaping the NASM precipitation is helpful for our understanding of

377 the TP's role in the global climate system. Previous studies mostly focus on the TP impact on Asian

378 monsoon precipitation, while we highlight the connection between the TP topography and North

379 American monsoon precipitation and show that the existence of the TP leads to more humid NAM

380 climate. The results obtained in this study may be model dependent. For example, the horizontal

381 resolution is reported to be crucial for adequately representing the NAM by accurately resolve the

382 summertime low-level flow along the Gulf of California (Pascale et al., 2019). The NAM is also

383 affected by SST biases. The excessive cold tongue is a common feature in general circulation model

384 (Wen et al., 2020), which may alter the response of NASM precipitation to TP uplift. Although this is

385 a highly idealized modeling study with some model limitations, this work helps explain the

386 quantitative role of the TP in the real world. The evolution of tropical American climate during the

387 geological time period is not only related to regional circulation change, but also links to Asian high

388 land regions.

Our modeling results may have applications for paleoclimate study. For example, previous

390 works use fossil flowers to reconstruct the Miocene climate over south Mexico and show that the 
environmental conditions of the Chiapas is warmer and drier than in the present (Hernández et al.,

392 2020), which is consistent with our study. Su et al (2018) use climate models and show that water

393 vapor is divergent over tropical American continent without the TP, indicating that the tropical

394 American continent is much drier in a world without the TP. Huber and Goldner (2012) analyze the

395 Eocene monsoons and show that a high TP can generate precipitation over central American region,

396 consistent with this study. As suggested in previous works, the elevated TP heating can affect the

397 Asian-Pacific Oscillation intensity, with positive anomalies of tropospheric temperature deviation

398 over the Eurasian continent and negative anomalies of tropospheric temperature deviation over the

399 central and eastern North Pacific, as well as the Atlantic Ocean (Nan et al., 2009; Duan et al., 2012).

400 The teleconnection pattern is also found in our studies.

This work may also have some implications on modern climate. The TP uplift can induce 402 thermal heating at middle troposphere by lapse rate relationship, which shows resemblance to the rapid warming over the TP in the past decades (Duan and Xiao, 2015). There are many studies show that the TP heating could enhance East Asian summer rainfall (Wang et al., 2008), the monsoon rainfall variability in Pakistan (Wang et al., 2019), more studies should focus on the climate change 406 outside the Asian continent, i.e., the North American and North Atlantic to highlight the importance 407 of TP in shaping the global climate.

408 Acknowledgement: This work is supported by the NSF of China (Nos. 91737204, 41725021, 409 41376007, 41630527 and 4201101394) and the Fundamental Research Funds for the Central 410 Universities: B210201009. The experiments were performed on the supercomputers at the Chinese 411 National Supercomputer Centre in Tianjin (Tian-He No. 1). 
413 An, Z., J. Kutzbach, W. Prell, et al., 2001: Evolution of Asian monsoons and phased uplift of the 414 Himalaya-Tibetan plateau since Late Miocene times. Nature, 411(6833): 62-66.

415 Boos, W. R., Z. Kuang, 2010: Dominant control of the South Asian monsoon by orographic insulation $416 \quad$ versus plateau heating. Nature, 463(7278): 218-222.

417 Boos, W. R., R. L. Korty, 2016: Regional energy budget control of the intertropical convergence zone 418 and application to mid-Holocene rainfall. Nature Geoscience, 9(12): 892-897.

419 Bush, A. B. G., S. G. H. Philander, 1999: The climate of the Last Glacial Maximum: Results from a 420 coupled atmosphere-ocean general circulation model. Journal of Geophysical Research: 421 Atmospheres, 104(D20): 24509-24525.

422 Castro, C. L., T. B. McKee, Sr. R. A. Pielke, 2001: The relationship of the North American monsoon to 423 tropical and North Pacific sea surface temperatures as revealed by observational analyses. J. Clim.,

Chen, S., K. Wei, W. Chen, et al., 2014: Regional changes in the annual mean Hadley circulation in 426 recent decades. Journal of Geophysical Research: Atmospheres, 119(13): 7815-7832.

427 Cheng, J., S. Hu, C. Gao, et al., 2020: On the discrepancies in the changes in the annual mean Hadley 428 circulation among different regions and between CMIP5 models and reanalyses. Theoretical and 429 Applied Climatology, 141(3): 1475-1491.

430 Chou, C., J. D. Neelin, C. A. Chen, and J. Y. Tu, 2009: Evaluating the "rich-get-richer"' mechanism in 431 tropical precipitation change under global warming. J. Clim., 22, 1982-2005.

432 Clift, P. D., 2008: Greater Himalayan exhumation triggered by Early Miocene monsoon intensification. $433 \quad$ Nature Geoscience.

434 Cook, K. H., 2003: Role of continents in driving the Hadley cells. Journal of the atmospheric sciences, 435 60(7): 957-976. 
436

D'Agostino, R., P. Lionello, O. Adam, et al., 2017: Factors controlling Hadley circulation changes from the Last Glacial Maximum to the end of the 21st century. Geophysical Research Letters, 44(16): $8585-8591$.

Duan, A., G. Wu, Y. Liu, et al., 2012: Weather and climate effects of the Tibetan Plateau. Advances in Atmospheric Sciences, 29(5): 978-992.

Duan, A. M., Z. X. Xiao, 2015: Does the Climate Warming Hiatus Exist Over the Tibetan Plateau? Sci. Rep., 5:13711.

de Jesús Hernández-Hernández, M., J. A. Cruz, C. Castañeda-Posadas, 2020: Paleoclimatic and Vegetation Reconstruction of the Miocene Southern Mexico using Fossil Flowers. Journal of South American Earth Sciences, 104: 102827.

Fallah, B., U. Cubasch, K. Prömmel, et al., 2016: A numerical model study on the behaviour of Asian summer monsoon and AMOC due to orographic forcing of Tibetan Plateau. Clim. Dyn., 47(5): $1485-1495$.

Harrison, T. M., P. Copeland, W. S. F. Kidd, and A. Yin, 1992: Raising Tibet. Science, 255, 1663-1670.

Higgins, R. W., Y. Yao, X. L. Wang, 1997: Influence of the North American monsoon system on the US summer precipitation regime. J. Clim., 10(10): 2600-2622.

Hoskins, B. J., and D. J. Karoly, 1981: The steady linear response of a spherical atmosphere to thermal and orographic forcing. J. Atmos. Sci., 38, 1179-1196.

Hu, S., J. Cheng, J. Chou, 2017: Novel three-pattern decomposition of global atmospheric circulation: generalization of traditional two-dimensional decomposition. Clim. Dyn., 49(9): 3573-3586.

Hu, S., J. Chou, J. Cheng, 2018: Three-pattern decomposition of global atmospheric circulation: part I — decomposition model and theorems. Clim. Dyn., 50(7): 2355-2368.

Huber, M., A. Goldner, 2012: Eocene monsoons. Journal of Asian Earth Sciences, 44: 3-23. 
Iqbal, M. J., S. U. Rehman, S. Hameed, et al., 2019: Changes in Hadley circulation: the Azores high and winter precipitation over tropical northeast Africa. Theoretical and Applied Climatology, 137(3): 2941-2948.

Jiang, D., Z. Ding, H. Drange, et al., 2008: Sensitivity of East Asian climate to the progressive uplift

Julian, P. R., R. M. Chervin, 1978: A study of the Southern Oscillation and Walker Circulation phenomenon. Mon. Weather. Rev., 106:1433-1451.

Kroon, D., T. Steens, and S. R. Troelstra, 1991: Onset of the monsoonal related upwelling in the western Arabian Sea as revealed by planktonic foraminifera, in Prell, W. L., et al., Proceedings of the Ocean Drilling Program, Scientific results, Volume 117: College Station, Texas, Ocean Drilling Program, p. 257-263.

Kushnir, Y., R. Seager, M. Ting, N. Naik, J. Nakamura, 2010: Mechanisms of tropical Atlantic SST influence on North American precipitation variability. J. Clim. 23, 5610-5628.

Lintner, B. R., W. R. Boos, 2019: Using atmospheric energy transport to quantitatively constrain South Pacific convergence zone shifts during ENSO. J. Clim., 32(6): 1839-1855.

Liu, B., T. Zhou, 2017: Atmospheric footprint of the recent warming slowdown. Scientific Reports, 7(1): $1-7$.

Liu, F., J. Chai, B. Wang, et al., 2016: Global monsoon precipitation responses to large volcanic eruptions. Scientific Reports, 6(1): 1-11.

Liu, X., Z. Y. Yin, 2002: Sensitivity of East Asian monsoon climate to the uplift of the Tibetan Plateau. Palaeogeography, Palaeoclimatology, Palaeoecology, 183(3-4): 223-245.

Mamalakis, A., J. T. Randerson, J. Y. Yu, et al., 2021: Zonally contrasting shifts of the tropical rain belt 483 
484

485

486

487

488

489

490

491

492

493

494

495

496

497

498

499

500

501

502

503

504

505

506

507

Molnar, P., W. Boos, D. Battisti, 2010: Orographic Controls on Climate and Paleoclimate of Asia: Thermal and Mechanical Roles for the Tibetan Plateau. Annual Review of Earth and Planetary Sciences, 38(1): 77-102.

Nan, S. L., P. Zhao, and S. Yang, 2009: Springtime tropospheric temperature over the Tibetan Plateau and evolution of the tropical Pacific SST. J. Geophys. Res., 114, D10104.

Park, H. S., J. C. Chiang, S. Bordoni, 2012: The mechanical impact of the Tibetan Plateau on the seasonal evolution of the South Asian monsoon. J. Clim., 25(7): 2394-2407.

Parsons, L. A., J. Yin, J. T. Overpeck, et al., 2014: Influence of the Atlantic Meridional Overturning Circulation on the monsoon rainfall and carbon balance of the American tropics. Geophysical Research Letters, 41(1): 146-151.

Pascale, S., L. M. V. Carvalho, D. K. Adams, et al., 2019: Current and Future Variations of the Monsoons of the Americas in a Warming Climate. Current Climate Change Reports, 5(3): $125-144$.

Prell, W. L., J. E. Kutzbach, 1992: Sensitivity of the Indian monsoon to forcing parameters and implications for its evolution. Nature, 360(6405): 647-652.

Prell, W. L., J. E. Kutzbach, 1992: Sensitivity of the Indian monsoon to forcing parameters and implications for its evolution. Nature, 360(6405): 647-652.

Quade, J., T. E. Cerling, J. R. Bowman, 1989: Development of Asian monsoon revealed by marked ecological shift during the latest Miocene in northern Pakistan. Nature, 342(6246): 163-166.

Rossby, C. G., 1939: Relation between variations in the intensity of the zonal circulation of the atmosphere and the displacements of the semi-permanent centers of action. J. Mar. Res., 2:38-55.

Su, B., D. Jiang, R. Zhang, et al., 2018: Difference between the North Atlantic and Pacific meridional overturning circulation in response to the uplift of the Tibetan Plateau. Climate of the Past, 14(6): $751-762$. 
508

509

510

\section{1}

512

513

514

515

516

517

518

519

520

521

Tang, H., A. Micheels, J. T. Eronen, et al., 2013: Asynchronous responses of East Asian and Indian summer monsoons to mountain uplift shown by regional climate modelling experiments. Clim. Dyn., 40(5): 1531-1549.

Wang, B., J. Liu, H. J. Kim, et al., 2012: Recent change of the global monsoon precipitation (1979-2008). Clim. Dyn., 39(5): 1123-1135.

Wang, B., M. Biasutti, M. P. Byrne, et al., 2021: Monsoons climate change assessment. Bulletin of the American Meteorological Society, 102(1): E1-E19.

Wang, B., Q. Ding, 2008: Global Monsoon: Dominant Mode of Annual Variation in the Tropics. Dynamics of Atmospheres and Oceans, 44(3-4): 165-183.

Wang, C., L. Zhang, S. K. Lee, L. Wu, C. R. Mechoso, 2014: A global perspective on CMIP5 climate model biases. Nat. Clim. Change, 4, 201-205.

Wang, Z., S. Yang, A. Duan, et al., 2019: Tibetan Plateau heating as a driver of monsoon rainfall variability in Pakistan. Clim. Dyn., 52(9): 6121-6130.

Webster, P. J., V. O. Magana, et al., 1998: Monsoons: processes, predictability, and the prospects for prediction. J. Geophys. Res., 103:14451-14510.

Wen, Q., J. Yao, K. Döös, et al., 2018: Decoding hosing and heating effects on global temperature and meridional circulations in a warming climate. J. Clim., 31(23): 9605-9623.

Wen, Q., H. Yang, 2020: Investigating the role of the Tibetan Plateau in the formation of Pacific meridional overturning circulation. J. Clim., 33(9): 3603-3617.

Wen, Q., K. Döös, Z. Lu, et al., 2020: Investigating the Role of the Tibetan Plateau in ENSO Variability. J. Clim., 33(11): 4835-4852.

Wu, G., Y. Liu, B. Dong, et al., 2012: Revisiting Asian monsoon formation and change associated with Tibetan Plateau forcing: I. Formation. Clim. Dyn., 39(5): 1169-1181.

Xie, S. P., C. Deser, G. A. Vecchi, et al., 2010: Global warming pattern formation: Sea surface temperature and rainfall. J. Clim., 23(4): 966-986. 
533 Yang, H., Q. Wen, J. Yao, et al., 2017: Bjerknes compensation in meridional heat transport under

534 freshwater forcing and the role of climate feedback. J. Clim., 30(14): 5167-5185.

535 Yang, H., Q. Wen, 2020: Investigating the role of the Tibetan Plateau in the formation of Atlantic 536 meridional overturning circulation. J. Clim., 33(9): 3585-3601.

537 Yim, S. Y., B. Wang, J. Liu, et al., 2014: A comparison of regional monsoon variability using monsoon 538 indices. Clim. Dyn., 43(5-6): 1423-1437.

539 Zhang, K. X., G. C. Wang, J. L. Ji, et al., 2010: Paleogene-Neogene stratigraphic realm and 540 sedimentary sequence of the Qinghai-Tibet Plateau and their response to uplift of the plateau. $541 \quad$ Science China Earth Sciences, 53(9): 1271-1294.

542 Zhang, W., T. Zhou, and L. Zhang, 2017: Wetting and greening Tibetan Plateau in early summer in 543 recent decades. J. Geophys. Res., 122, 5808-5822.

544 Zhao, P., Y. Zhu, and R. Zhang, 2007: An Asian-Pacific teleconnection in summer tropospheric 545 temperature and associated Asian climate variability. Climate Dyn., 29, 293-303.

546 Zhao, P., B. Wang, J. Liu, et al., 2016: Summer precipitation anomalies in Asia and North America 547 induced by Eurasian non-monsoon land heating versus ENSO. Scientific reports, 6(1): 1-8.

548 Zhao, P., S. Yang, R. Wu, Z. Wen, J. Chen, and H. Wang, 2012: Asian origin of interannual variations 549 of summer climate over the extratropical North Atlantic Ocean. J. Clim., 25, 6594-6609. 
Figure 1 Topography configuration (units: m) for (a) CTRL and (b) NoTP.

559

560

561

562

563

564

Figure 2 (a) Time evolution of percentage changes in Atlantic meridional overturning circulation (AMOC) with light blue curves representing results from 10 ensemble fully coupled runs. The AMOC index is defined as the maximum streamfunction in the range of $0^{\circ}-10^{\circ} \mathrm{C}$ over $20^{\circ}-70^{\circ} \mathrm{N}$ in the Atlantic. (b) Equilibrium changes in geopotential height (shading; m) and wind (vector; m/s) at $850 \mathrm{hPa}$ during boreal summer in SOM runs. (c) Equilibrium changes in surface air temperature $\left(\mathrm{SAT} ;{ }^{\circ} \mathrm{C}\right)$ during boreal summer in SOM runs. (d) and (e) are the same as (b) and (c), but for fully coupled runs.

Figure 3 (a) Time evolution of changes in North American summer monsoon (NASM) precipitation (mm/day). Blue curves are for precipitation change, with solid curve for fully coupled runs and dashed curve for SOM runs. Red curves are for percentage changes in precipitation, with solid curve for fully coupled runs and dashed curve for SOM runs. (b) Equilibrium changes in precipitation (mm/day) during boreal summer in SOM runs. (c) Equilibrium changes in surface humidity (shading; g/kg) during boreal summer in SOM runs with mean values (purple contours; g/kg) from CTRL_SOM. (d) and (e) are the same as (b) and (c) but for fully coupled runs. In (b)-(e), the stippling areas indicate the difference exceeding 95\% confidence level, determined by a two-tailed Student's t test. The black contours denote the North American monsoon region, which is defined as the region where the local summer precipitation minus local winter precipitation exceeding $2 \mathrm{~mm}$ /day and the local summer precipitation exceeds $55 \%$ of annual rainfall in CTRL run. In (d), the purple contours denote the NAM region by using GPCP data from 1979-2018.

Figure 4 Equilibrium changes in (a) precipitation $\left(P^{\prime}\right)$, (b) evaporation $\left(E^{\prime}\right)$, (c) thermodynamic component of vertical moisture advection $\left(-\left\langle\omega q^{\prime}\right\rangle\right)$, (d) dynamic component of vertical moisture 

advection $\left(-\left\langle\omega^{\prime} q\right\rangle\right)$, (e) thermodynamic component of horizontal moisture advection $\left(-\left\langle V \cdot \nabla q^{\prime}\right\rangle\right)$, and (f) dynamic component of horizontal moisture advection $\left(-\left\langle V^{\prime} \cdot \nabla q\right\rangle\right)$ in SOM runs during boreal summer. Units: mm/day. The black contours denote the North American monsoon region.

Figure 5 Same as Fig. 4 but for fully coupled runs. The black contours denote the North American monsoon region.

Figure 6 Bar char for the mean changes in (a) precipitation and its contribution terms and (b) dynamic component of vertical moisture advection and its contribution terms. Orange bar is for SOM runs and blue bar is for fully coupled runs. In (a), The meaning of labels at $\mathrm{x}$-axis is the same as that in Fig. 4. In (b), $-\omega_{W}^{\prime} q$ denotes the dynamic term due to zonal circulation change and $-\omega_{H}{ }^{\prime} q$ denotes the dynamic term due to meridional circulation change. Units: $\mathrm{mm} / \mathrm{day}$. All values are from boreal summer.

Figure 7 Left panel is the annual mean state of vertical velocity (units: $\mathrm{Pa} / \mathrm{s}$ ) at $500 \mathrm{hPa}$ in (a) CTRL, (b) NoTP, (c) CTRL_SOM, and (d) CTRL_NoTP. Right panel is the same as left panel but for boreal summer. Positive value is for upward motion. The black contours denote the North American monsoon region.

Figure 8 Left panel is the annual mean state of precipitation (units: mm/day) in (a) CTRL, (b) NoTP, (c) CTRL_SOM, and (d) CTRL_NoTP. Right panel is the same as left panel but for boreal summer. The black contours denote the North American monsoon region.

Figure 9 (a) Total vertical velocity and its (b) meridional component, (c) zonal component and (d) residual in CTRL_SOM at $500 \mathrm{hPa}$ during boreal summer. (e)-(h) are the same as (a)-(d) but for CTRL. The decomposition are based on 3P-DGAC method. Units: Pa/s. 
602 Figure 10 Equilibrium changes in (a) total vertical velocity (units: $\mathrm{Pa} / \mathrm{s}$ ) and its (b) meridional 603 component and (c) zonal component at $500 \mathrm{hPa}$ during boreal summer in SOM runs, respectively. 604 (d)-(f) are the same as (a)-(c) but for fully coupled runs. The red rectangle outlines the eastern 605 Pacific-Atlantic section.

606 Figure 11 Mass stream function $\left(10^{11} \mathrm{~kg} / \mathrm{s}\right)$ averaged between $120^{\circ} \mathrm{W}$ and $20^{\circ} \mathrm{W}$ during boreal 607 summer in (a) SOM runs and (c) fully coupled runs. The black contours denote the mean values 608 in a word with TP while the shadings denote the difference. (b) and (d) are the vertical averaged 609 mass stream function in (a) and (c) correspondingly.

610 Figure 12 (a) Equilibrium changes in zonal mean precipitation (mm/day; red curve) and SAT $\left({ }^{\circ} \mathrm{C}\right.$; 611 dashed black curve) during boreal summer over the eastern Pacific-Atlantic section in SOM runs. 612 (b) Equilibrium changes in precipitation ( $\mathrm{mm} /$ day; shading) and the location of Intertropical 613 Convergence Zone (ITCZ) during boreal summer in SOM runs. The green dots are for ITCZ in a 614 world without the TP while the black dots are for ITCZ in a world with the TP. (c)-(d) are the 615 same as (a)-(b) but for fully coupled runs.

616 Figure 13 (a) Changes in net atmospheric energy input during boreal summer between CTRL and 617 NoTP. (b) Same as (a) but only shows the TOA component. (c) Same as (a) but only shows the 618 surface component. Units: $\mathrm{W} / \mathrm{m}^{2}$. (d) Changes in the divergent meridional component of the 619 atmospheric energy transport (AET) during boreal summer in fully coupled runs. Units: $10^{7} \mathrm{~W} / \mathrm{m}$. 620 The red arrow represents the southward transport of AET. The calculation for AET follows 621 Mamalakis et al (2021). 
Figures
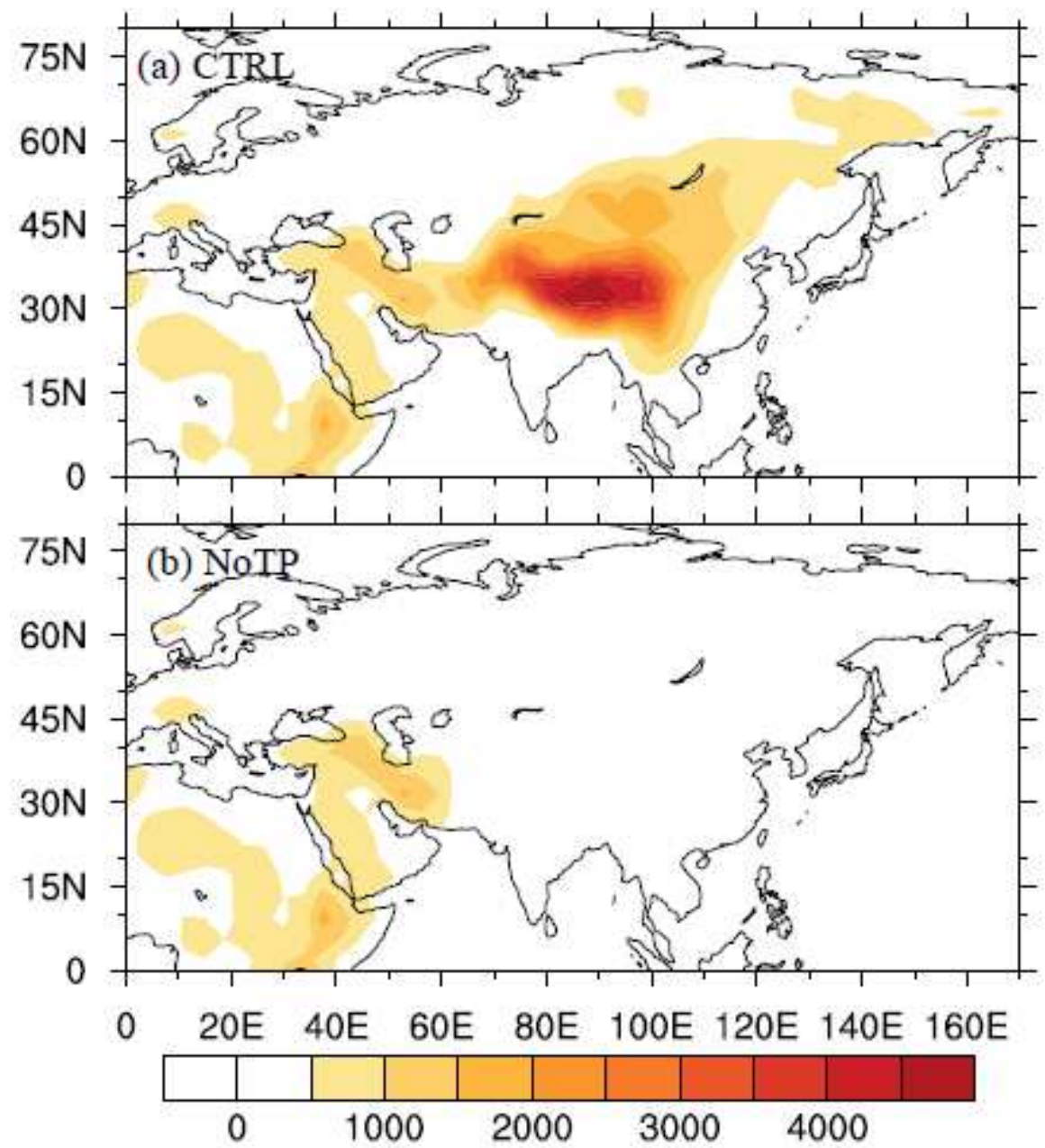

\section{Figure 1}

Topography configuration (units: $m$ ) for (a) CTRL and (b) NoTP. Note: The designations employed and the presentation of the material on this map do not imply the expression of any opinion whatsoever on the part of Research Square concerning the legal status of any country, territory, city or area or of its authorities, or concerning the delimitation of its frontiers or boundaries. This map has been provided by the authors. 


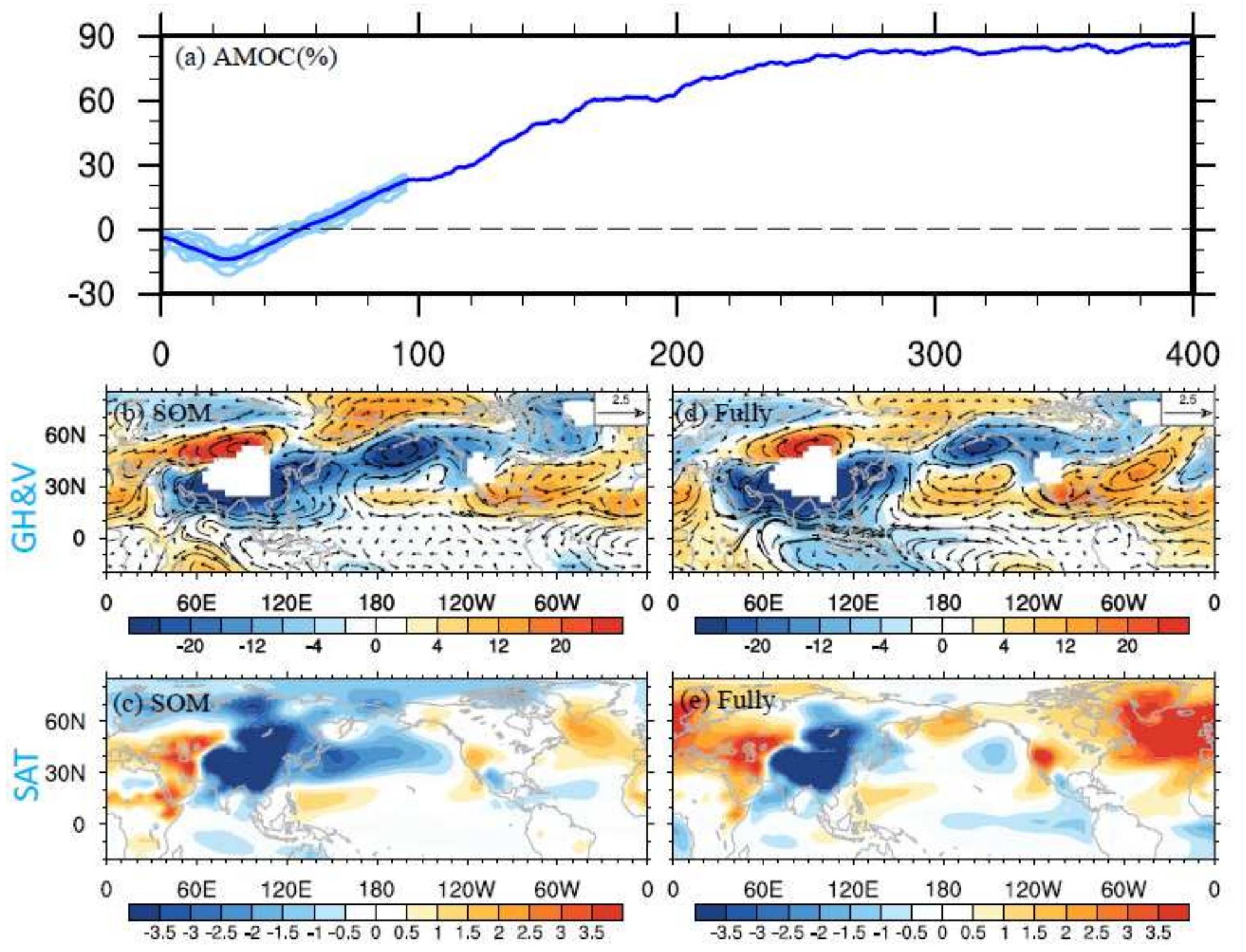

Figure 2

(a) Time evolution of percentage changes in Atlantic meridional overturning circulation (AMOC) with light blue curves representing results from 10 ensemble fully coupled runs. The AMOC index is defined as the maximum streamfunction in the range of $0^{\circ}-10^{\circ} \mathrm{C}$ over $20^{\circ}-70^{\circ} \mathrm{N}$ in the Atlantic. (b) Equilibrium changes in geopotential height (shading; $\mathrm{m}$ ) and wind (vector; $\mathrm{m} / \mathrm{s}$ ) at $850 \mathrm{hPa}$ during boreal summer in SOM runs. (c) Equilibrium changes in surface air temperature (SAT; ${ }^{\circ} \mathrm{C}$ ) during boreal summer in SOM runs. (d) and (e) are the same as (b) and (c), but for fully coupled runs. Note: The designations employed and the presentation of the material on this map do not imply the expression of any opinion whatsoever on the part of Research Square concerning the legal status of any country, territory, city or area or of its authorities, or concerning the delimitation of its frontiers or boundaries. This map has been provided by the authors. 

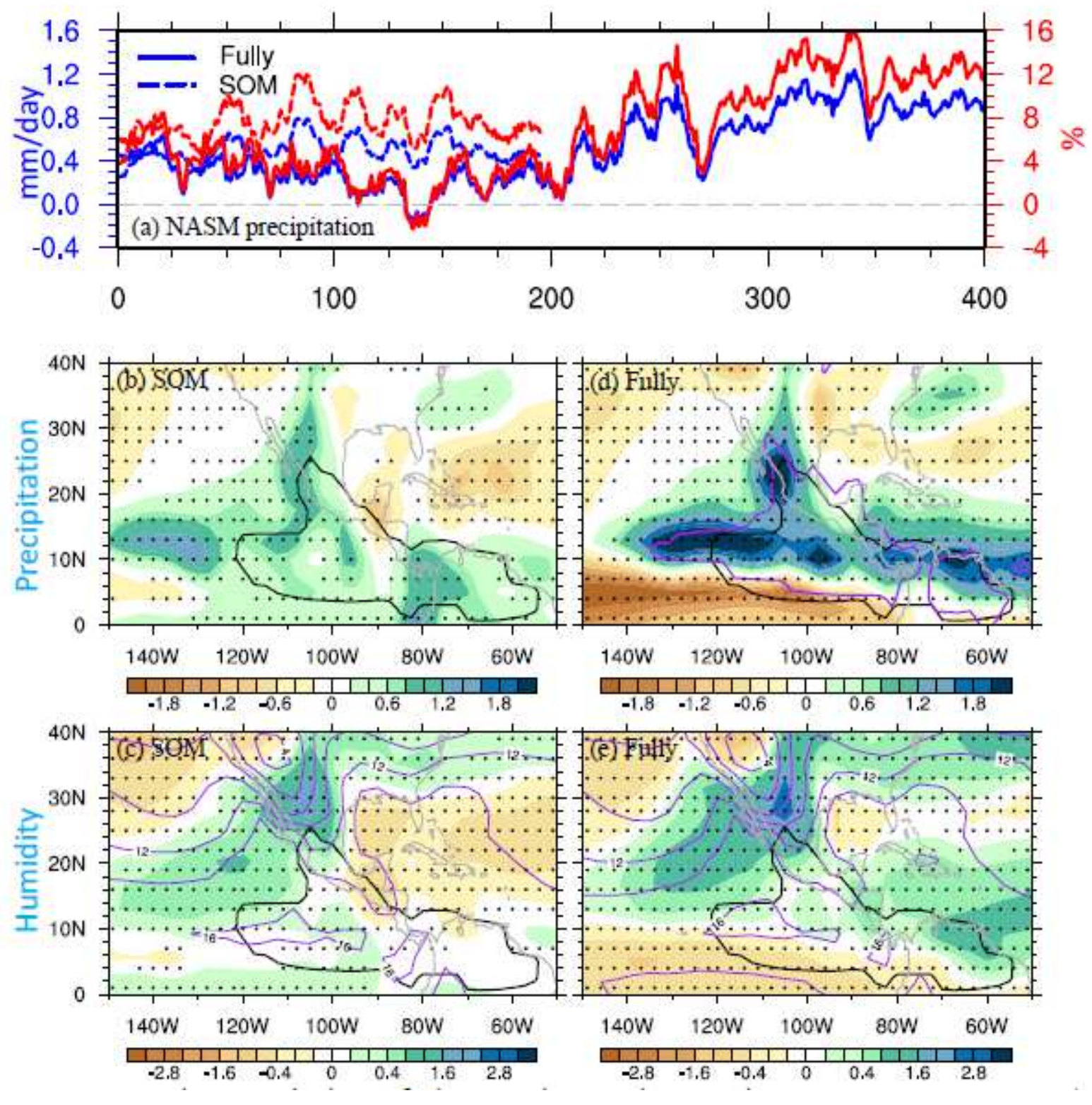

Figure 3

(a) Time evolution of changes in North American summer monsoon (NASM) precipitation ( $\mathrm{mm} /$ day). Blue curves are for precipitation change, with solid curve for fully coupled runs and dashed curve for SOM runs. Red curves are for percentage changes in precipitation, with solid curve for fully coupled runs and dashed curve for SOM runs. (b) Equilibrium changes in precipitation $(\mathrm{mm} /$ day) during boreal summer in SOM runs. (c) Equilibrium changes in surface humidity (shading; $\mathrm{g} / \mathrm{kg}$ ) during boreal summer in SOM runs with mean values (purple contours; g/kg) from CTRL_SOM. (d) and (e) are the same as (b) and (c) but for fully coupled runs. In (b)-(e), the stippling areas indicate the difference exceeding $95 \%$ confidence level, determined by a two-tailed Student's $t$ test. The black contours denote the North American monsoon region, which is defined as the region where the local summer precipitation minus local winter precipitation exceeding $2 \mathrm{~mm}$ /day and the local summer precipitation exceeds $55 \%$ of annual rainfall in CTRL run. In (d), the purple contours denote the NAM region by using GPCP data from 1979-2018. 

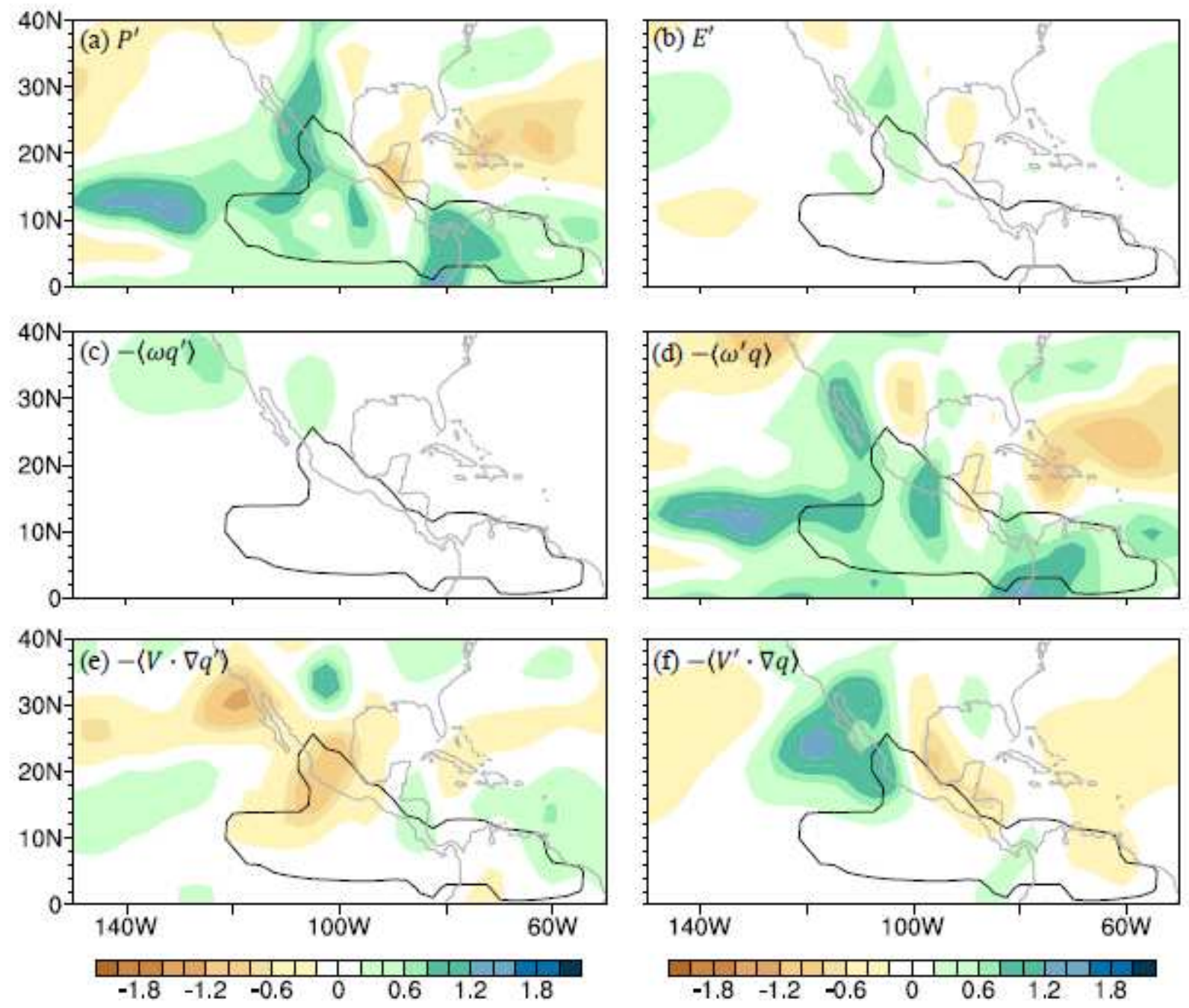

Figure 4

Equilibrium changes in (a) precipitation ( $\left.P^{\prime}\right),(b)$ evaporation ( $\left.E^{\prime}\right),(c)$ thermodynamic component of vertical moisture advection (- $\left.\nabla \omega q^{\prime} \varangle\right)$, (d) dynamic component of vertical moisture advection (- $\left.\nabla \omega^{\wedge \prime} q \nabla\right)$, (e) thermodynamic component of horizontal moisture advection (- $\mathbb{V} \mathbf{V} \mathbb{\nabla} \mathbb{q} \rrbracket)$, and (f) dynamic component of

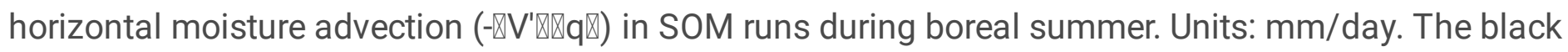
contours denote the North American monsoon region. 

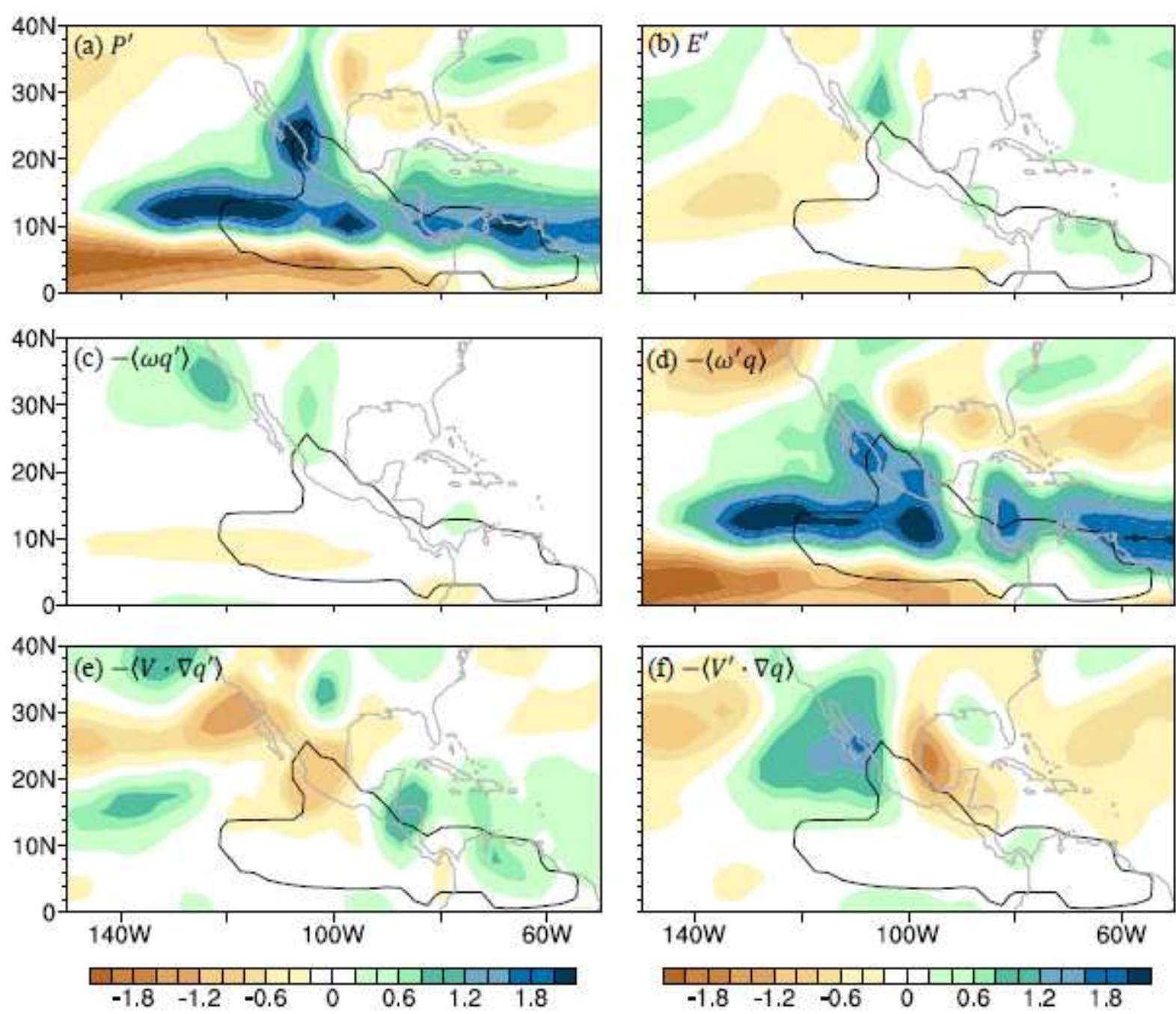

Figure 5

Same as Fig. 4 but for fully coupled runs. The black contours denote the North American monsoon region. 

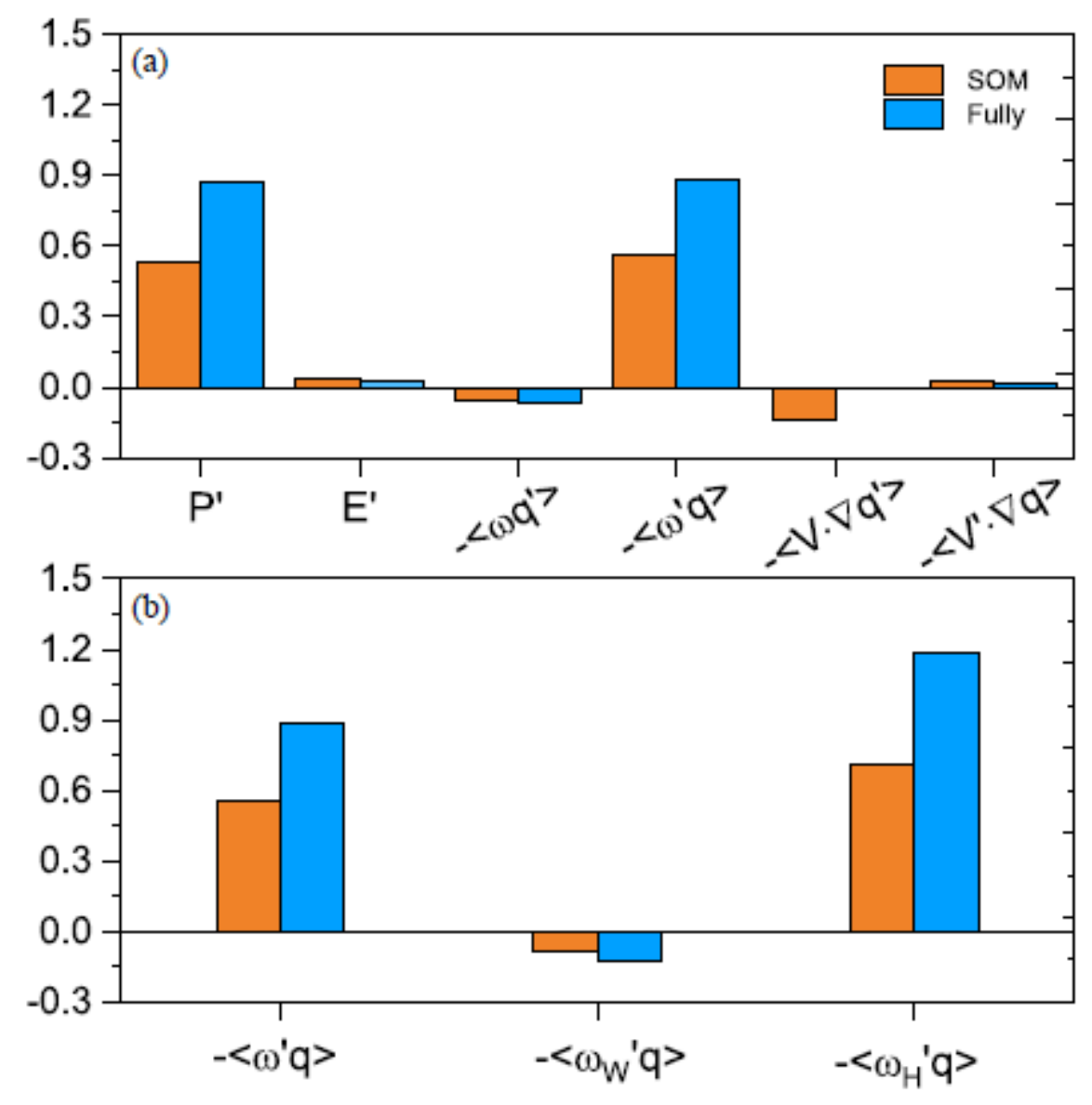

Figure 6

Bar char for the mean changes in (a) precipitation and its contribution terms and (b) dynamic component of vertical moisture advection and its contribution terms. Orange bar is for SOM runs and blue bar is for fully coupled runs. In (a), The meaning of labels at $x$-axis is the same as that in Fig. 4. In (b), - $\omega \_W ' q$ denotes the dynamic term due to zonal circulation change and - $\omega \_H$ 'q denotes the dynamic term due to meridional circulation change. Units: $\mathrm{mm} /$ day. All values are from boreal summer. 


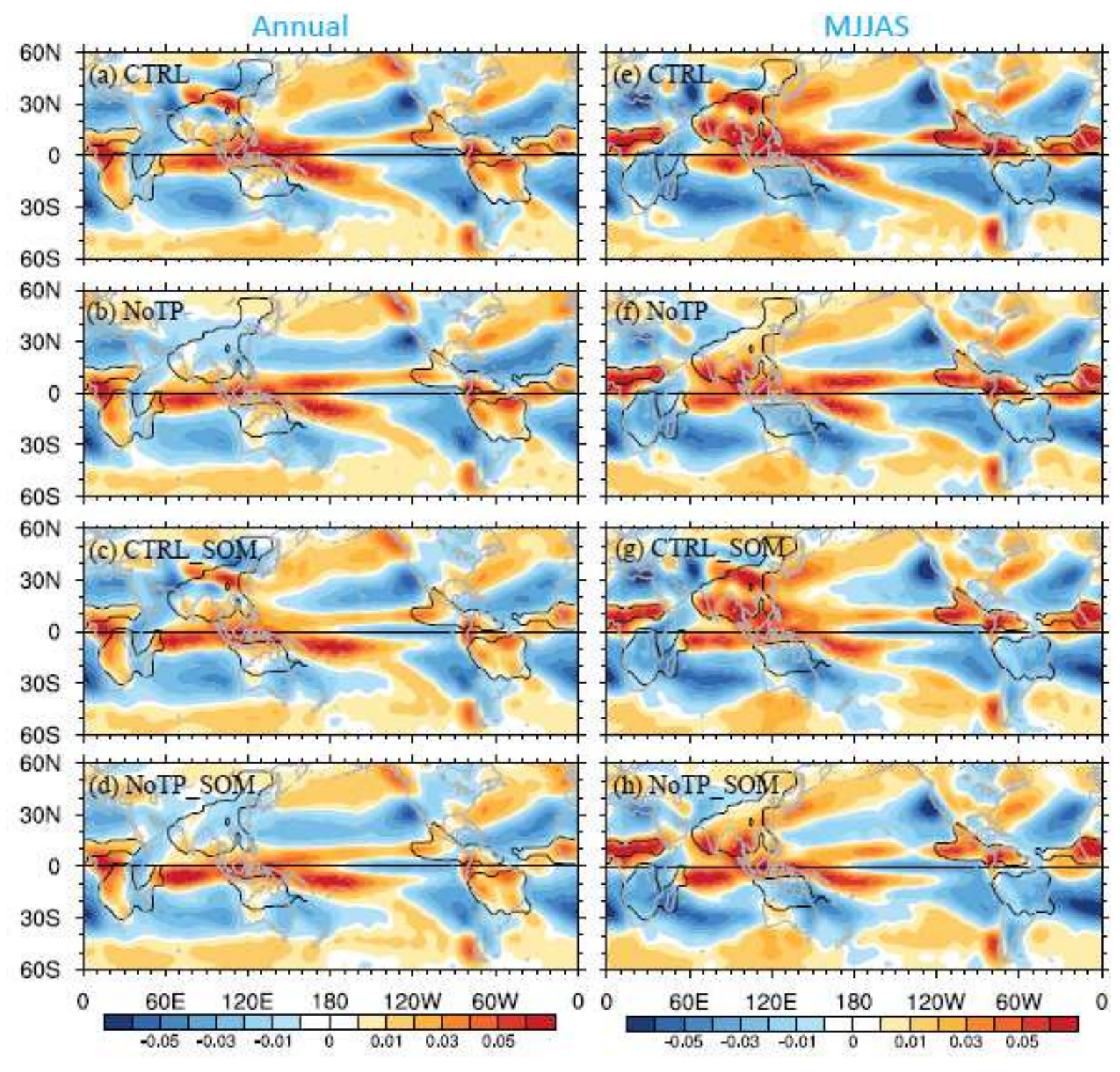

Figure 7

Left panel is the annual mean state of vertical velocity (units: Pa/s) at $500 \mathrm{hPa}$ in (a) CTRL, (b) NoTP, (c) CTRL_SOM, and (d) CTRL_NoTP. Right panel is the same as left panel but for boreal summer. Positive value is for upward motion. The black contours denote the North American monsoon region. Note: The designations employed and the presentation of the material on this map do not imply the expression of any opinion whatsoever on the part of Research Square concerning the legal status of any country, territory, city or area or of its authorities, or concerning the delimitation of its frontiers or boundaries. This map has been provided by the authors. 

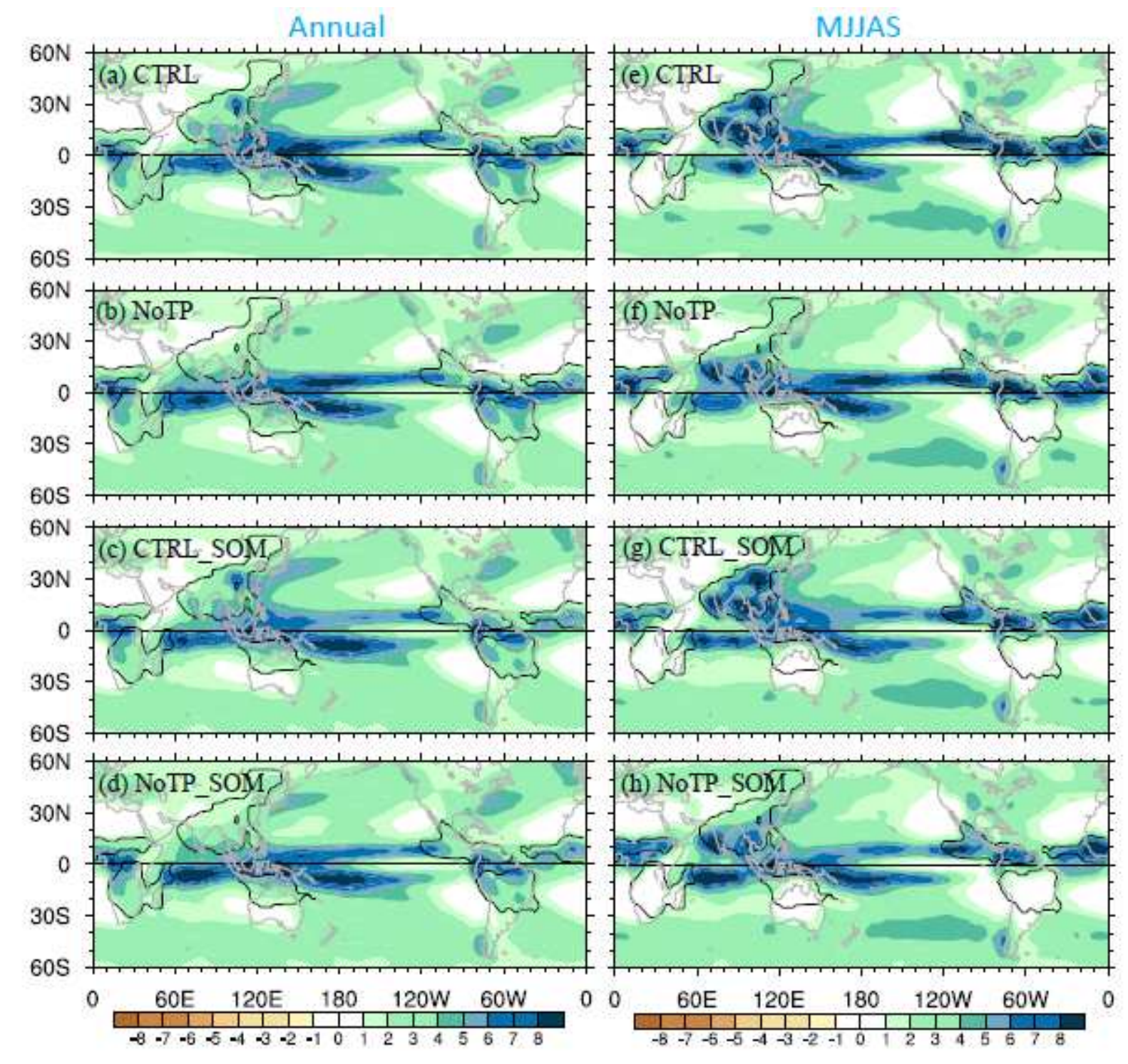

\section{Figure 8}

Left panel is the annual mean state of precipitation (units: $\mathrm{mm} /$ day) in (a) CTRL, (b) NoTP, (c) CTRL_SOM, and (d) CTRL_NoTP. Right panel is the same as left panel but for boreal summer. The black contours denote the North American monsoon region. Note: The designations employed and the presentation of the material on this map do not imply the expression of any opinion whatsoever on the part of Research Square concerning the legal status of any country, territory, city or area or of its authorities, or concerning the delimitation of its frontiers or boundaries. This map has been provided by the authors. 


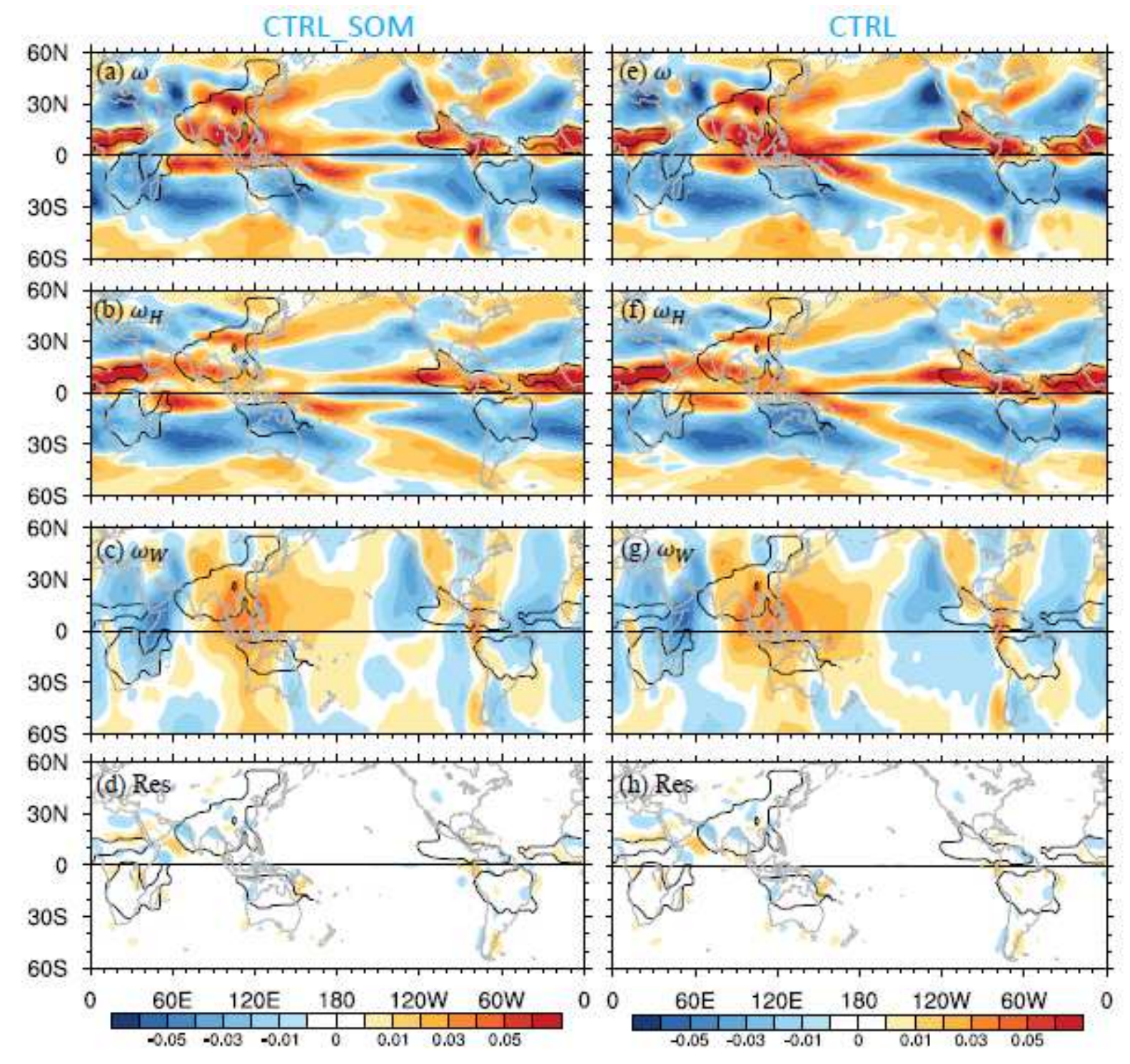

\section{Figure 9}

(a) Total vertical velocity and its (b) meridional component, (c) zonal component and (d) residual in CTRL_SOM at $500 \mathrm{hPa}$ during boreal summer. (e)-(h) are the same as (a)-(d) but for CTRL. The decomposition are based on 3P-DGAC method. Units: Pa/s. Note: The designations employed and the presentation of the material on this map do not imply the expression of any opinion whatsoever on the part of Research Square concerning the legal status of any country, territory, city or area or of its authorities, or concerning the delimitation of its frontiers or boundaries. This map has been provided by the authors. 
SOM

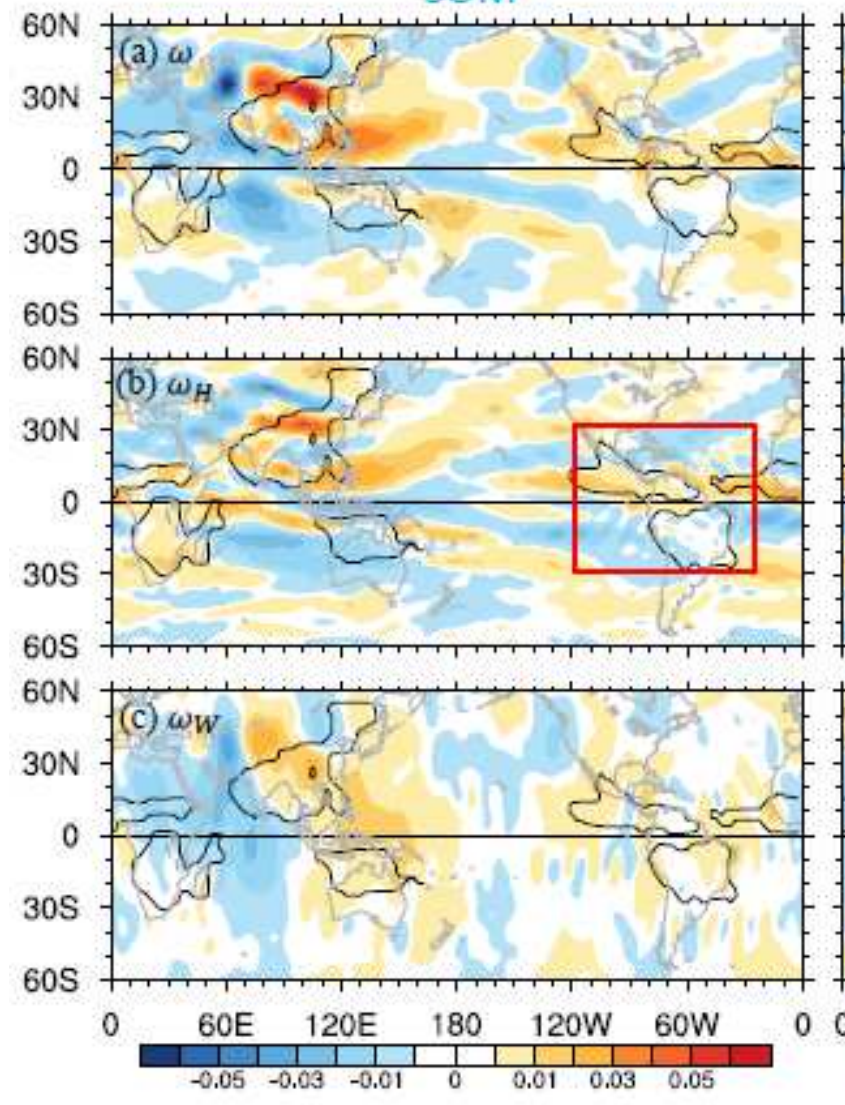

Fully
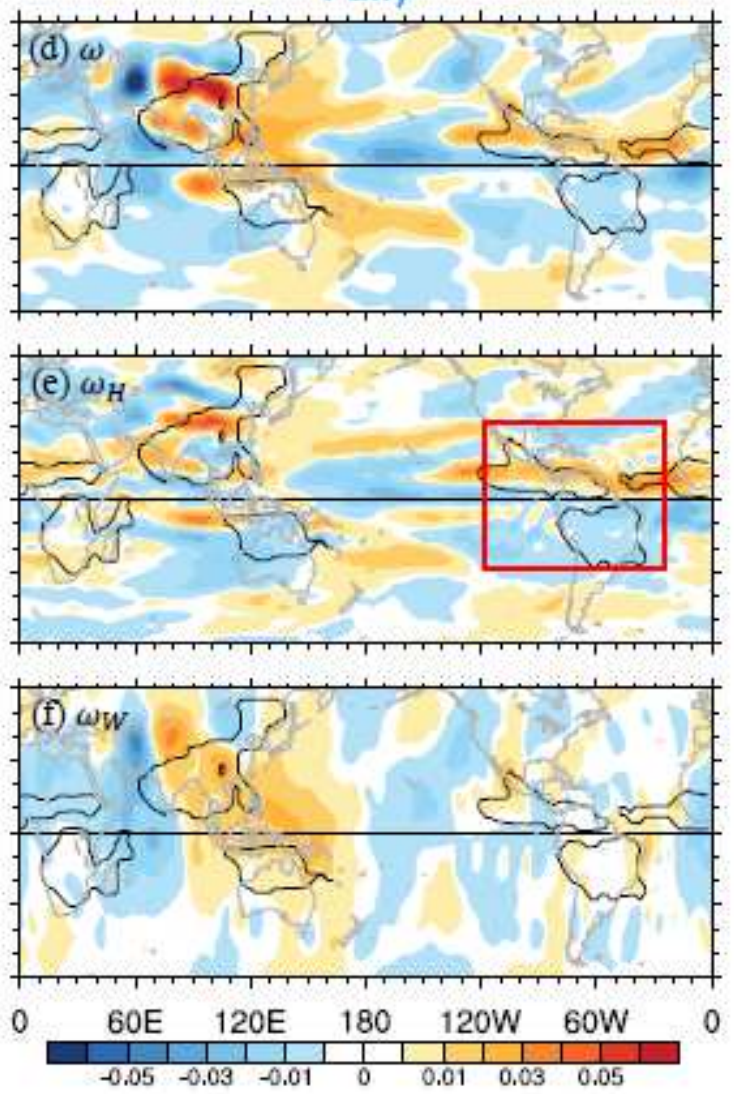

Figure 10

Equilibrium changes in (a) total vertical velocity (units: $\mathrm{Pa} / \mathrm{s}$ ) and its (b) meridional component and (c) zonal component at $500 \mathrm{hPa}$ during boreal summer in SOM runs, respectively. (d)-(f) are the same as (a)(c) but for fully coupled runs. The red rectangle outlines the eastern Pacific-Atlantic section. Note: The designations employed and the presentation of the material on this map do not imply the expression of any opinion whatsoever on the part of Research Square concerning the legal status of any country, territory, city or area or of its authorities, or concerning the delimitation of its frontiers or boundaries. This map has been provided by the authors. 

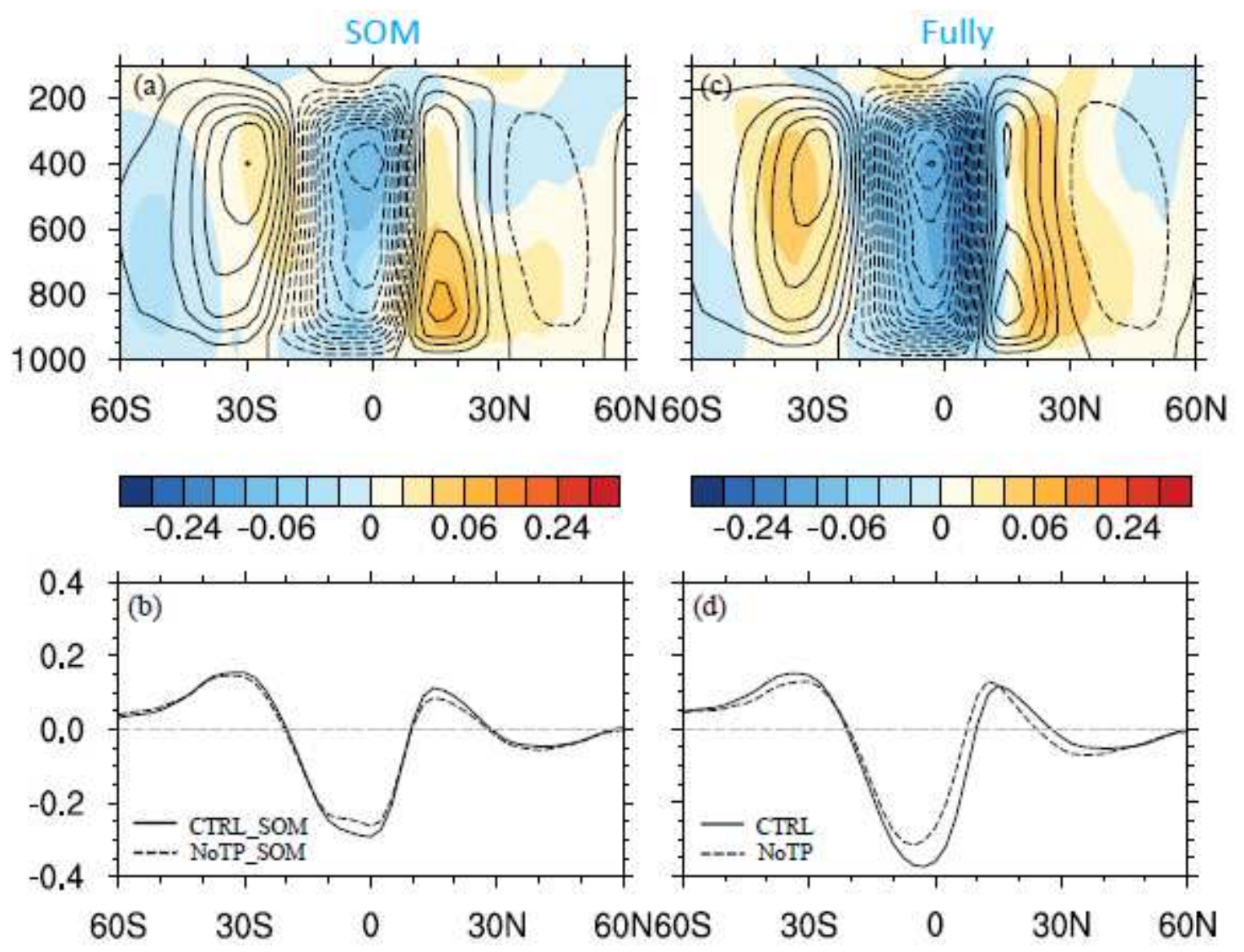

Figure 11

Mass stream function $(1011 \mathrm{~kg} / \mathrm{s}$ ) averaged between $120 \mathrm{WW}$ and $20 \mathrm{WW}$ during boreal summer in (a) SOM runs and (c) fully coupled runs. The black contours denote the mean values in a word with TP while the shadings denote the difference. (b) and (d) are the vertical averaged mass stream function in (a) and (c) correspondingly.
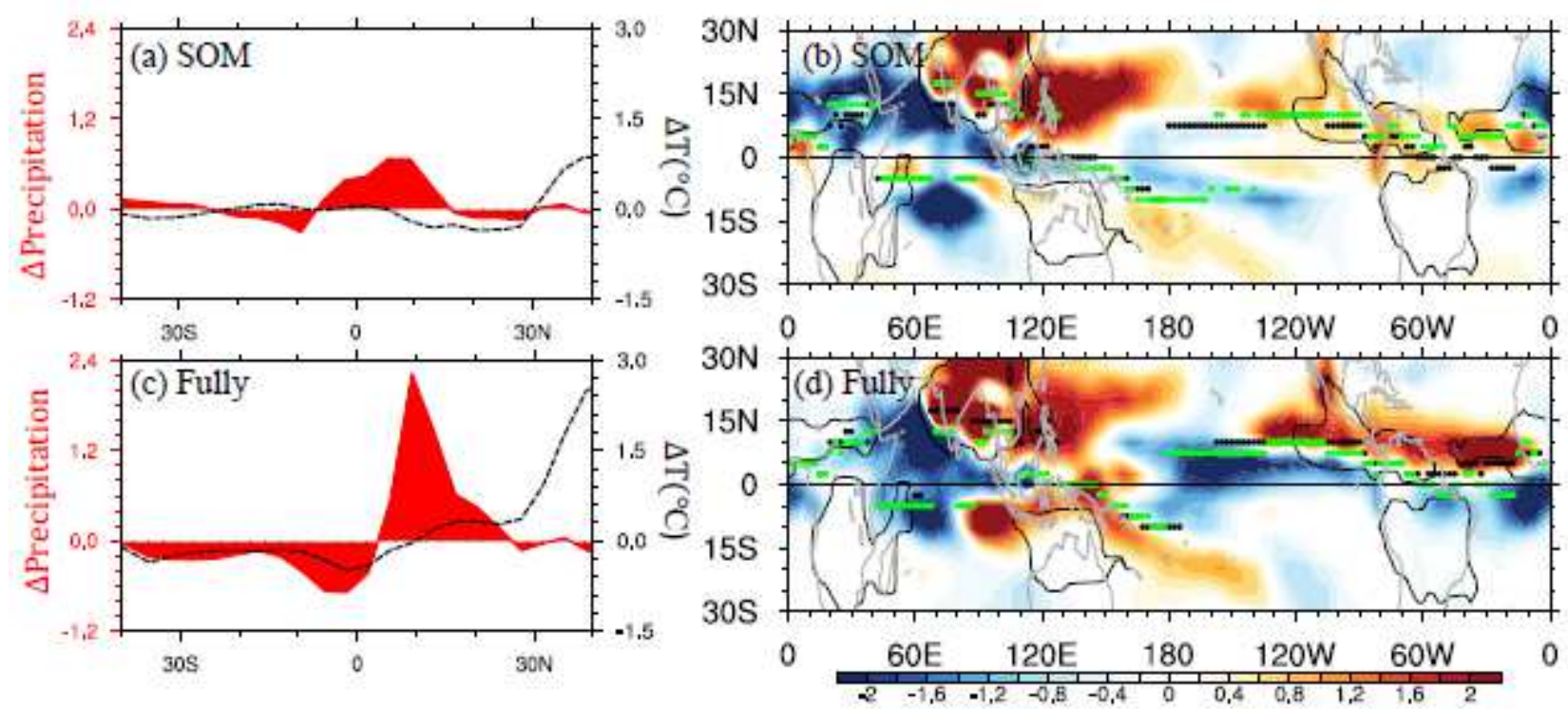

Figure 12 
(a) Equilibrium changes in zonal mean precipitation ( $\mathrm{mm} /$ day; red curve) and SAT (oC; dashed black curve) during boreal summer over the eastern Pacific-Atlantic section in SOM runs. (b) Equilibrium changes in precipitation ( $\mathrm{mm} /$ day; shading) and the location of Intertropical Convergence Zone (ITCZ) during boreal summer in SOM runs. The green dots are for ITCZ in a world without the TP while the black dots are for ITCZ in a world with the TP. (c)-(d) are the same as (a)-(b) but for fully coupled runs. Note: The designations employed and the presentation of the material on this map do not imply the expression of any opinion whatsoever on the part of Research Square concerning the legal status of any country, territory, city or area or of its authorities, or concerning the delimitation of its frontiers or boundaries. This map has been provided by the authors.
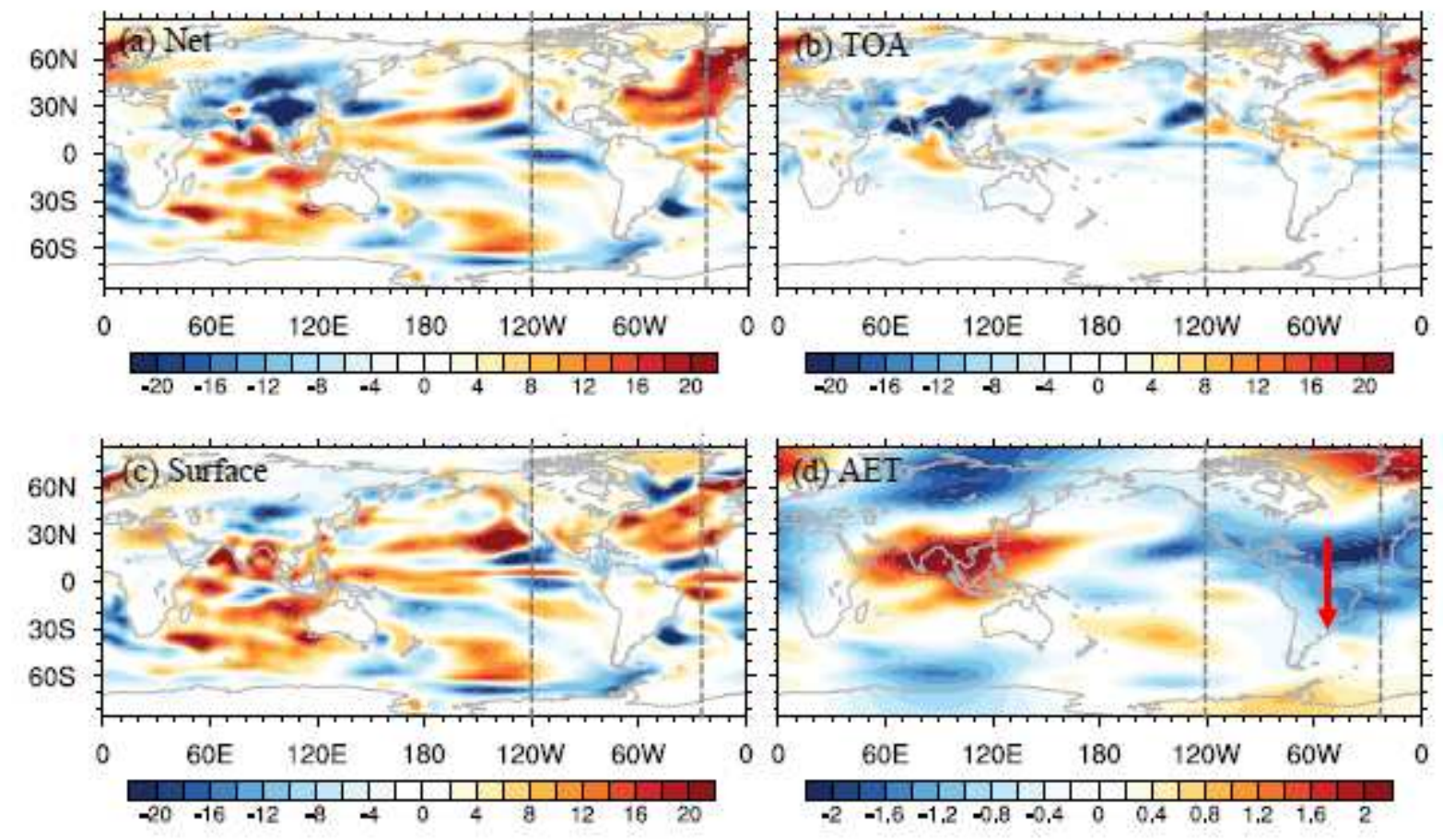

\section{Figure 13}

(a) Changes in net atmospheric energy input during boreal summer between CTRL and NoTP. (b) Same as (a) but only shows the TOA component. (c) Same as (a) but only shows the surface component. Units: $\mathrm{W} / \mathrm{m} 2$. (d) Changes in the divergent meridional component of the atmospheric energy transport (AET) during boreal summer in fully coupled runs. Units: $107 \mathrm{~W} / \mathrm{m}$. The red arrow represents the southward transport of AET. The calculation for AET follows Mamalakis et al (2021). Note: The designations employed and the presentation of the material on this map do not imply the expression of any opinion whatsoever on the part of Research Square concerning the legal status of any country, territory, city or area or of its authorities, or concerning the delimitation of its frontiers or boundaries. This map has been provided by the authors. 